\title{
ShIP Wakes AND TheIr RAdAR IMAges
}

\author{
Arthur M. Reed ${ }^{1}$ and Jerome H. Milgram ${ }^{2}$ \\ ${ }^{I}$ David Taylor Model Basin, Carderock Division, Naval Surface Warfare Center, West \\ Bethesda, Maryland 20817; e-mail: ReedAM@nswccd.navy.mil \\ ${ }^{2}$ Department of Ocean Engineering, Massachusetts Institute of Technology, Cambridge, \\ Massachusetts 02139; e-mail: jmilgram@mit.edu
}

Key Words Kelvin wakes, centerline wakes, remote sensing of ship wakes

- Abstract Remote observations of a surface ship wake using synthetic aperture radar (SAR) show distinct features such as a dark trailing centerline region, bright V-images aligned at some angle to the ship's path, and, sometimes, either the transverse or the diverging waves of the Kelvin-wave pattern. The dark region of relatively low radar backscatter is usually associated with a region that is relatively lacking in short wave components, whereas the bright line feature suggests a region of enhanced radar return within the apparent angular confines of the ship's usual Kelvin-wave pattern. This review provides a survey of remotely sensed wake images, the systems that have collected these images, and an overview of the theory of Kelvin wakes-a primary source of the phenomena that cause the dark centerline and bright V-images-with example predictions. The review concludes with a survey of the phenomena that cause the dark centerline returns and some example predictions of the radar reflectivity across these dark centerline returns.

\section{INTRODUCTION}

Ship wakes can be divided into Kelvin-wake parts and non-Kelvin-wake parts. The Kelvin wake is the far-field wave pattern resulting from the fluid mechanical flow around the ship hull. Kelvin-wake waves are the classical wave pattern of diverging and transverse waves as sketched in Figure 1.

Non-Kelvin-wake parts of ship wakes include some local features near the ship such as breaking bow and stern waves, the viscous wake containing the rotational flow from the ship's boundary layers, and some far-reaching manifestations of these features. Perhaps the most notable of these is the redistribution of natural surfactants on the ocean surface that, in turn, influences the damping of short sea waves. These tracks of diminished short waves can exist for tens of kilometers in light wind conditions Another far-reaching feature is the bubbly flow caused by breaking waves and the air ingested by the propeller. Interest in ship wakes has increased in recent years largely because of the ability to track some of the results of both Kelvin- and non-Kelvin-wake features by remote sensing. Bubble wakes can be tracked acoustically over many kilometers. However, radar sensing of the 


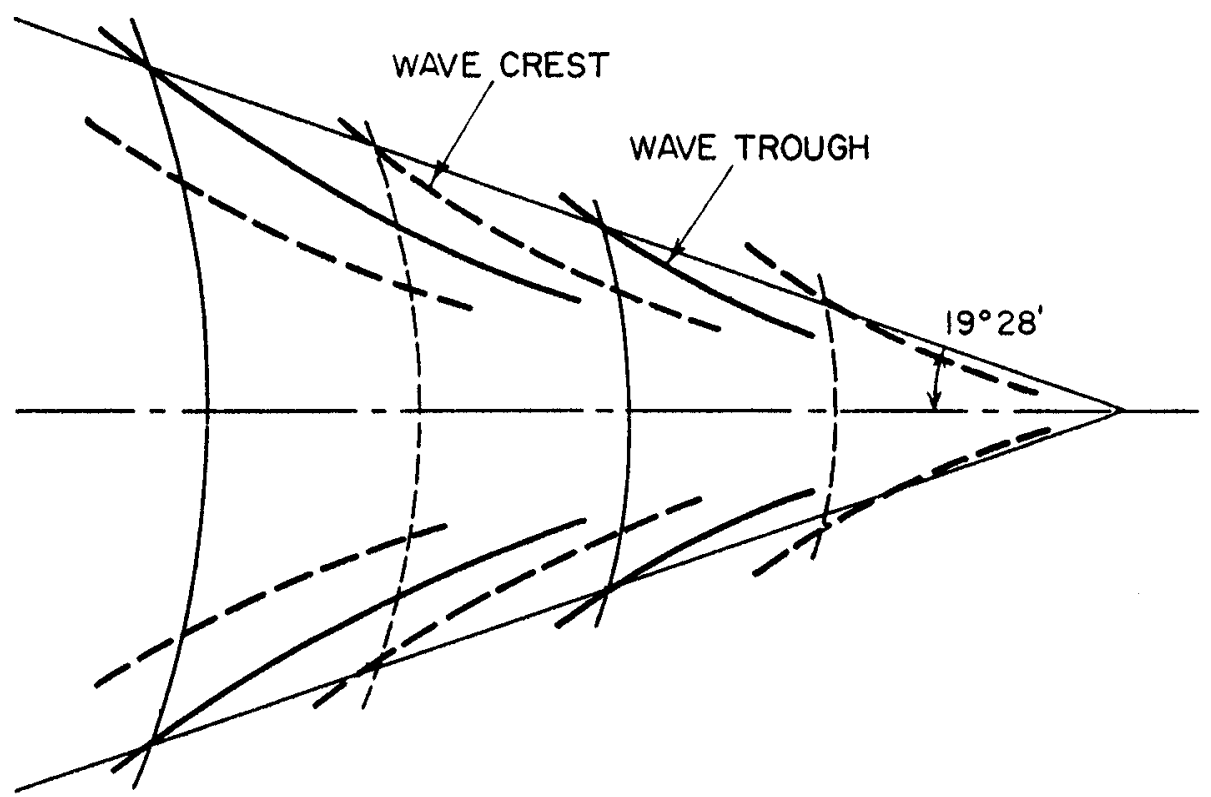

Figure 1 A Kelvin-wake pattern of diverging and transverse waves (from van Manen \& van Oossanen 1988).

surface manifestations has generated the most interest. Radar images of tracks of reduced, short sea-wave amplitudes caused by ship motion-generated zones of increased sea-surfactant concentration are often the most persistent remote-sensing feature. In addition, high-resolution radars can detect Kelvin-wave patterns through the modulation transfer function of the fluid velocities associated with the Kelvin waves. Of special interest are very narrow $\mathrm{V}$-shaped images with an included angle of just a few degrees. These come from Bragg scattering by the short diverging Kelvin waves near the centerline of the ship wake. There is controversy as to whether these narrow V-images come from the steady Kelvin wakes (Milgram 1988) or from related unsteady motions. In all likelihood, both steady and unsteady phenomena (Case et al. 1985) exist. The essential physics of the radar imaging is the same for each.

An ordinary real-aperture radar, supported on an aircraft or a spacecraft, yields poor resolution of ship wakes because of the small ratio of radar aperture length to the range distance from the radar to the sea. However, a synthetic aperture radar (SAR) can have a large effective aperture resulting in improved resolution on the order of a few meters. A SAR is a coherent side-looking radar that is flown on a moving platform, either an aircraft or a spacecraft.

The first viable SAR on a spacecraft used for looking at the ocean was on the NASA SEASAT satellite, which was launched and operated for five months in 1978. Its L-band SAR had a wavelength of $23 \mathrm{~cm}$ and an incidence angle of $23^{\circ}$. The SEASAT SAR obtained many swaths over water whose images revealed a 


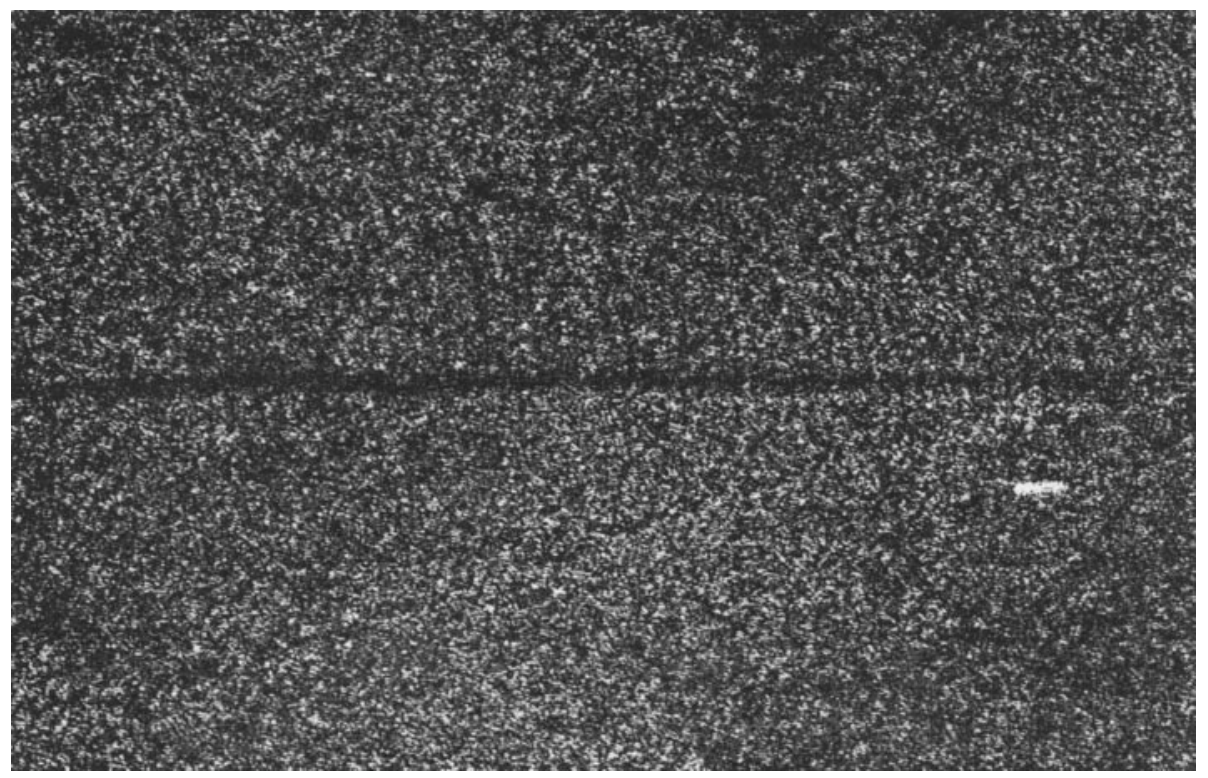

Figure 2 A SEASAT SAR image showing the Kelvin wake of a ship (from Case et al. 1985).

great number of ship wakes in addition to other ocean features such as internal waves and bathymetry. Many of these features were unexpected, and the SEASAT SAR became responsible for increased interest in ship wakes.

Figures 2, 3, and 4 are SEASAT images that identify various, surface ship wake manifestations. In these images, as in all SAR images, the bright areas correspond to areas of high radar cross section per unit area, $\sigma_{0}$, whereas those areas that are dark correspond to areas of low $\sigma_{0}$. The bright areas are regions of enhanced roughness or significant surface slope, and the dark areas are regions of reduced roughness. This enhanced $\sigma_{0}$ predominantly results from either specular reflection or Bragg scattering (Nathanson 1969).

Specular reflection corresponds to a mirror-like reflection of the radar signal off the ocean surface. This requires precise alignment between the radar antenna and the reflecting surface, which must be perpendicular to the look direction of the radar. Generally it occurs only from breaking waves.

Bragg scattering is a resonant scattering phenomena in which there is periodic contribution to the ocean-surface elevation whose component along the radar line of sight has a spatial frequency corresponding to one-half the radar wavelength (Beckmann \& Spizzichino 1963, Ulaby et al. 1982) or an integer multiple of this distance. In this resonant scattering, each wave contributes a very small amount to the radar return. However, because the wavelengths match, the contribution from each wave adds in phase with the contributions from the other waves, which results in significant total-radar return. The "Bragg waves" on the ocean surface are 


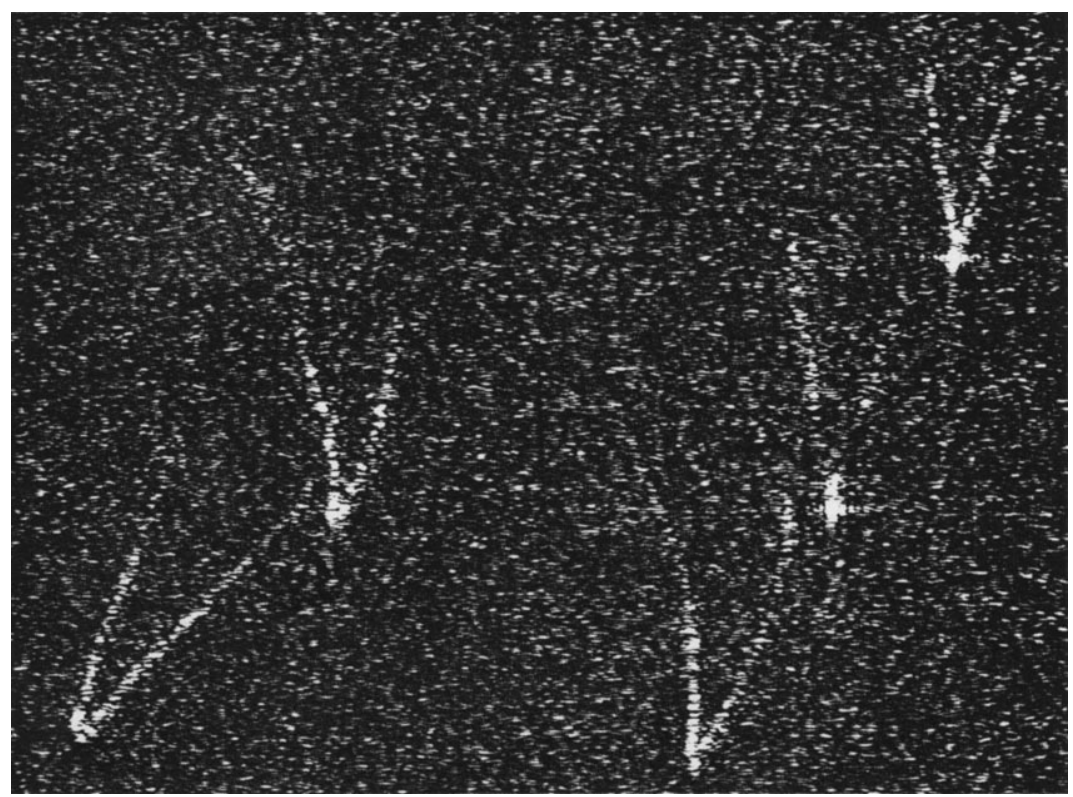

Figure 3 A SEASAT SAR image of a formation of commercial fishing boats (from Case et al. 1985).

either short gravity waves or capillary waves, depending on the radar frequency. The Bragg waves are generated by wind or by the ship itself. In SAR images under moderate to high wind conditions, bright features are visualized owing to wind-generated Bragg waves. When bright features are observed under light wind conditions, the SAR is probably sensing ship-generated Bragg waves.

Under moderate to high wind conditions, the background of the image is generally gray owing to the presence of Bragg waves. When ship wakes are observed on this gray background as alternating lighter and darker bands, the relatively uniform distribution of Bragg waves is being modulated by the presence of long gravity waves and currents in the wake. The presence of dark centerline returns in SAR images is due to the fact that the wake acts to suppress the Bragg waves in the centerline region.

Figure 2 shows an image of a classical, full Kelvin wake, which was sensed by SEASAT. The included angle is the classical Kelvin-wake angle of $39^{\circ}$; the Kelvin-wake arm returns are not bright, although they do have a slight bright halo on one side of the dark arms. Additionally, the transverse wave system created by the ship is visible. The dark centerline return can also be seen; it extends off of the image shown in Figure 2 to a length of about $7.7 \mathrm{~km}$. Also note, the bright ship return is displaced from the track owing to the Doppler shift inherent in SAR images for objects having motion in the range direction. The transverse wave system spacing or the distance of the offset of the bright ship return can be used 
1) IMAGE MADE BY SPACE DEPT. RAE FARNBOROUGH 27 FEB 84 RAE222 C>
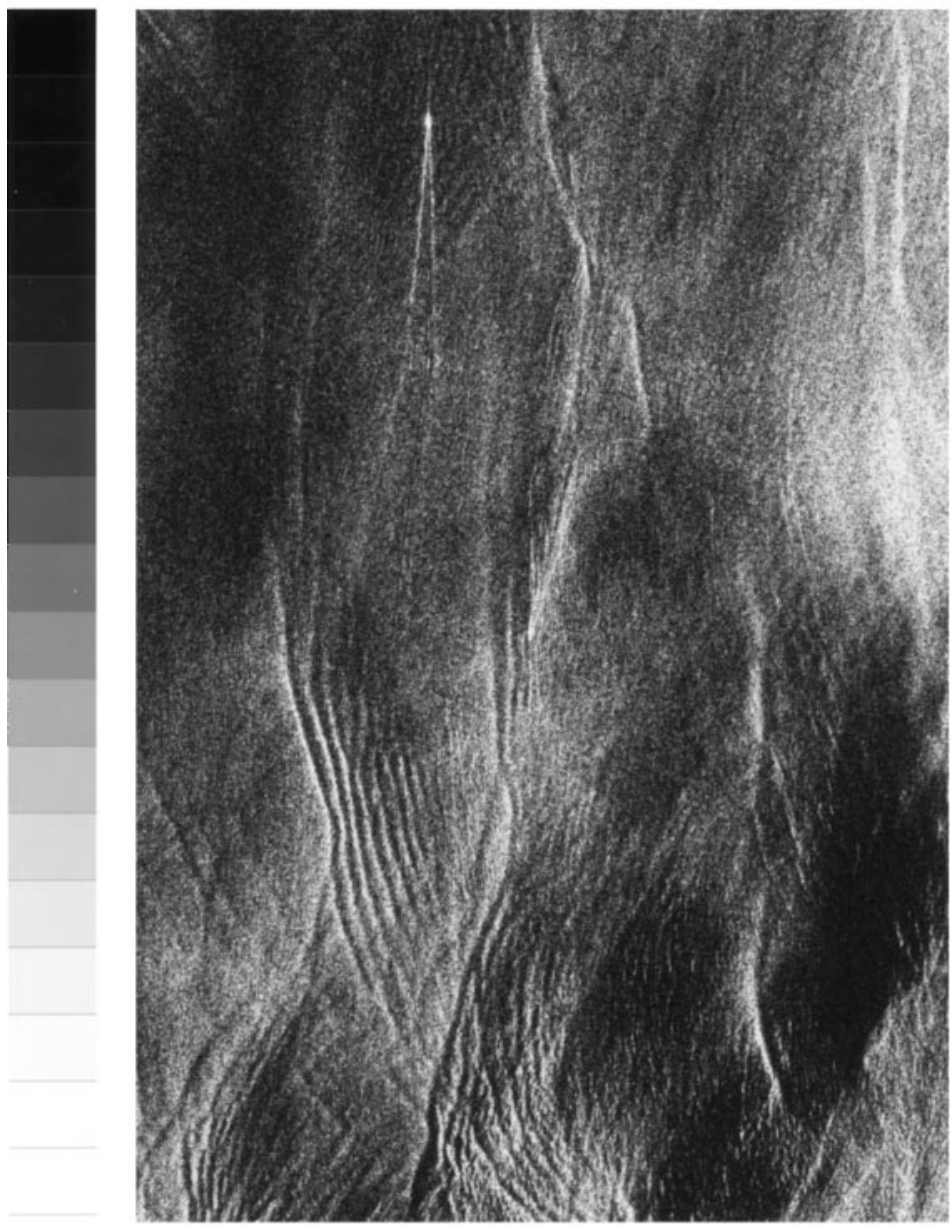

ESA/EARTHE * SEASAT I SAR IMACE * DIGITALIY PROCESSED AT THE ROYAL AIRCRAF THE 25 JAN 1984 USING PROCESSOR DEVELOPED BY SYSTEMS DESIQNERS LTD. \#IMAGE GRID PARAMEIERS ORIGIN, LAT 28:23:24 N ROTATION OF 79: $55: 13$ RROM TRUE NORTH = -22.25 DEC X AXIS $=12.00 \mathrm{M}$ * IMAGE PARAMEIERS IMAGE EXTENT. . TO $-5.000 \mathrm{kM}$ TO $38.000 \mathrm{KM}$ IMAEE CENTRE. LAT 28:31:50 N GMT OF IMAGE CENIRE $=11$ HR 17 MIN 51 SEC INCIDENCE ANQE AT
IMAGE CENTRE=22, $582 D E G$ * PROCESSING PARAMETERS RESOLUTION.

IN AZIMUTH $=24 \mathrm{M}$ SIDE OBE AZIMUTH $=-24.3$ DB RANGE $=-24,3$ D $=467$ SLB APERTURE WIDTH SUB APERTURE DOPPLER BANDWIDTH $=294 \mathrm{HZ}$ LOOK CENTRES RELATIVE COANIENM BORESIG NAMBER $4=-0.301$. NMBR $5=0.130$ DEG NIMBER $7=0.391$. ROTATION OF $+Y$ AXIS FROM THE ACROSS TRACK DIRECTION (INCR. RANGE) $=-89,989$ DEG

RUN IDENTIFIER 407004

Figure 4 A SEASAT SAR image showing numerous ship wakes (courtesy R.A.E. Farnborough).

to measure the speed of the ship. In this case both means give a ship speed of 22 knots.

Figure 3 is a SEASAT image from the Irish Sea. It is an enlargement covering approximately $3.1 \times 2.3 \mathrm{~km}$ and contains a formation of fishing vessels. The two distinctive things about this image are that the bright return angles vary between $20^{\circ}$ and $33^{\circ}$ and there appears to be no dark centerline return behind the ships. These bright angled returns are probably a Kelvin-wave manifestation, possibly from breaking waves in the diverging wave pattern or from solitons, which are nonlinear waves that can occur in a ship wake (Hall 1991). This group of bright 
returns is asymmetric with respect to the ships' tracks and has half angles ranging from $9^{\circ}$ to $19^{\circ}$, or just short of the classical $19^{\circ} 28^{\prime}$ half angle defined as the deep-water limit for any surface vehicle. These types of "mid-angle bright returns" also can occur on one or both sides of the ship.

Figure 4 (covering $38 \times 36 \mathrm{~km}$ ) is one of the most thoroughly investigated SEASAT images; it is frequently called the Canaveral image as it covers an area off Cape Canaveral, Florida. There are three visible ship returns as well as numerous areas covered by internal waves. The salient features in this image are the smallangle bright V-returns extending for considerable distances behind the ship body returns; the very long dark centerline return extending even further aft behind the bright ship return; and the shape of the ship return on the ship located near the center of the image. The small angle, bright returns are common in SAR ship-wake images; they occur on either one or both sides of the ship return. In this image, the half angles of these returns vary from $2^{\circ}$ to $8^{\circ}$. The dark return behind the ship identified here is approximately $24 \mathrm{~km}$ long.

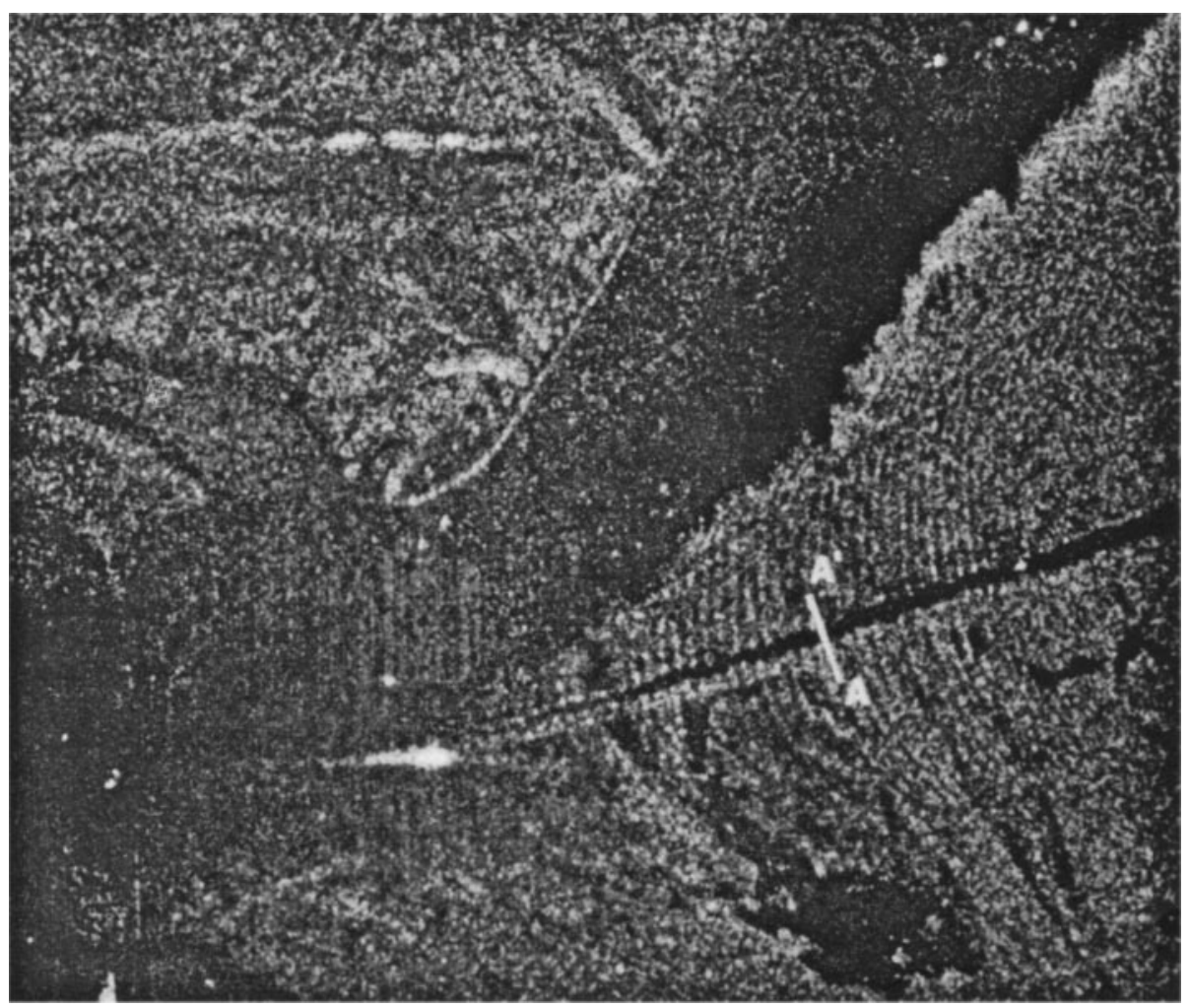

Figure 5 A SAR image showing the Kelvin wake of an ocean-going tugboat (from Lyden et al. 1988). 
Figure 5 also shows a full Kelvin wake. This image is from an aircraft-mounted SAR and was obtained in Georgia Straights during a program of sea trials conducted jointly by the Naval Ocean Systems Center (NOSC) and the Canadian Defense Research Establishment Pacific (DREP) called JOWIP (Hammond et al. 1985). The ship being imaged is the fleet tug USS Quapaw (ATF 110). The Quapaw is operating at 16.5 knots, which corresponds to a Froude number of 0.352 for this $59.4 \mathrm{~m}$ vessel. The image shows a complete set of transverse waves with a slightly bright line along the cuspline of the Kelvin wake. The dark region at the upper edge of the image is a calm area where the absence of wind or the presence of a surface film has resulted in total suppression of the background clutter.

Observations drawn from the analysis of many images are that wake manifestations seem to cover the entire range of half-angles between $1^{\circ}$ and the classical deep water $19^{\circ} 28^{\prime}$ full Kelvin-wave system half-angle. They appear either on one or both sides of the bright ship return. Bright narrow V-wake returns appear only in light winds $\left(U_{\text {wind }}<3 \mathrm{~m} / \mathrm{s}\right)$ and are often kilometers in length. Dark centerline returns due to damping of short sea waves are often even longer.

A few papers reviewing radar imagery of ship wakes were written approximately 10 years ago. Two examples of these are presented in Reed et al. (1990a) and Griffin et al. (1992).

\section{DESCRIPTION OF SHIP WAKES}

\subsection{Observational Features of Wakes}

Figure 6 is a photograph of a near ship wake. The cusplines of the Kelvin wake originating at the bow are clearly visible on both sides of the wake. Along the centerline a smooth, almost glassy region can be seen extending aft in the region in which the turbulent wake would normally reside. Between the Kelvin-wake cuspline and the smooth centerline region, various diverging waves are seen as radial-like spokes emanating from the ship. White water can be seen originating at the bow of the ship. The white-water regions at the bow and stern result from the breaking of steep waves generated near the hull. Observations of the dark centerline return in many wake images show that this region is generally significantly wider than the ship's beam in extent. The width of the dark centerline corresponds very well with the width of the region over which there are breaking bow and stern waves.

A schematic of a wake is illustrated in Figure 7. This wake is composed of white water, centerline wake, propeller wake, and Kelvin wake. As is seen in Figure 6, the white water generally results from a wave breaking at the bow, is often reinforced at the stern, and extends aft of the ship for two or three ship lengths. The centerline wake extends many ship lengths aft from the stern of the ship and incorporates the flow moving in the direction of the ship's travel due to the viscous drag, large-scale vortical flows, turbulence, and surfactant effects. Embedded within the centerline wake is the propeller outflow or propeller wake. Superimposed over this is the classical Kelvin-wave pattern or Kelvin wake. The 


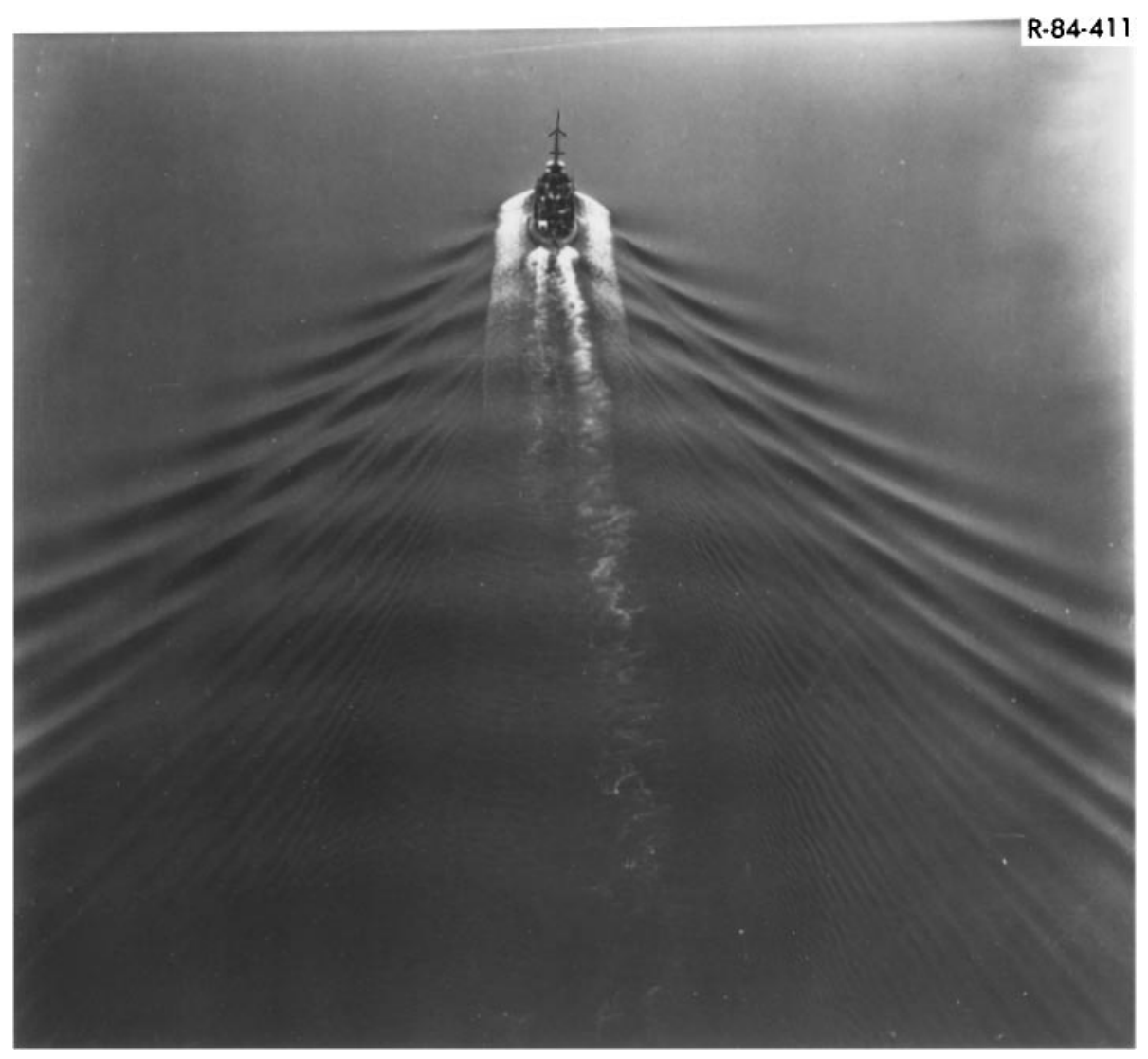

Figure 6 An oceangoing tugboat and its near wake (courtesy Donald Wyatt, SAIC).

wake lies on the ambient seaway that is made up of swell and wind waves, including short gravity and capillary waves. These short waves, particularly their attenuation near the ship track, play a major role in the radar imaging of centerline wakes.

The Kelvin-wave system's $19^{\circ} 28^{\prime}$ boundary lines (cusplines) and $35^{\circ} 16^{\prime}$ cuspcrest wave-vector orientation are illustrated in Figure 6 . The apex of the boundary lines is usually forward of the bow (Newman 1970). The transverse and divergent wave crests are visible optically for many ship lengths astern and to either side of the ship's path. The shorter, steeper divergent waves tend to be emphasized in aerial photographs. Under moderate to high wind conditions $\left(U_{\text {wind }}>3 \mathrm{~m} / \mathrm{s}\right)$, the transverse and cusp waves frequently appear in SAR images of the surface because these waves modulate the existing field of ambient Bragg waves (Lyden et al. 1988, Vesecky \& Stewart 1982).

Under moderate to high wind conditions the ambient surface is sufficiently rough so that, visually, the turbulent-wake surface appears smooth relative to the 


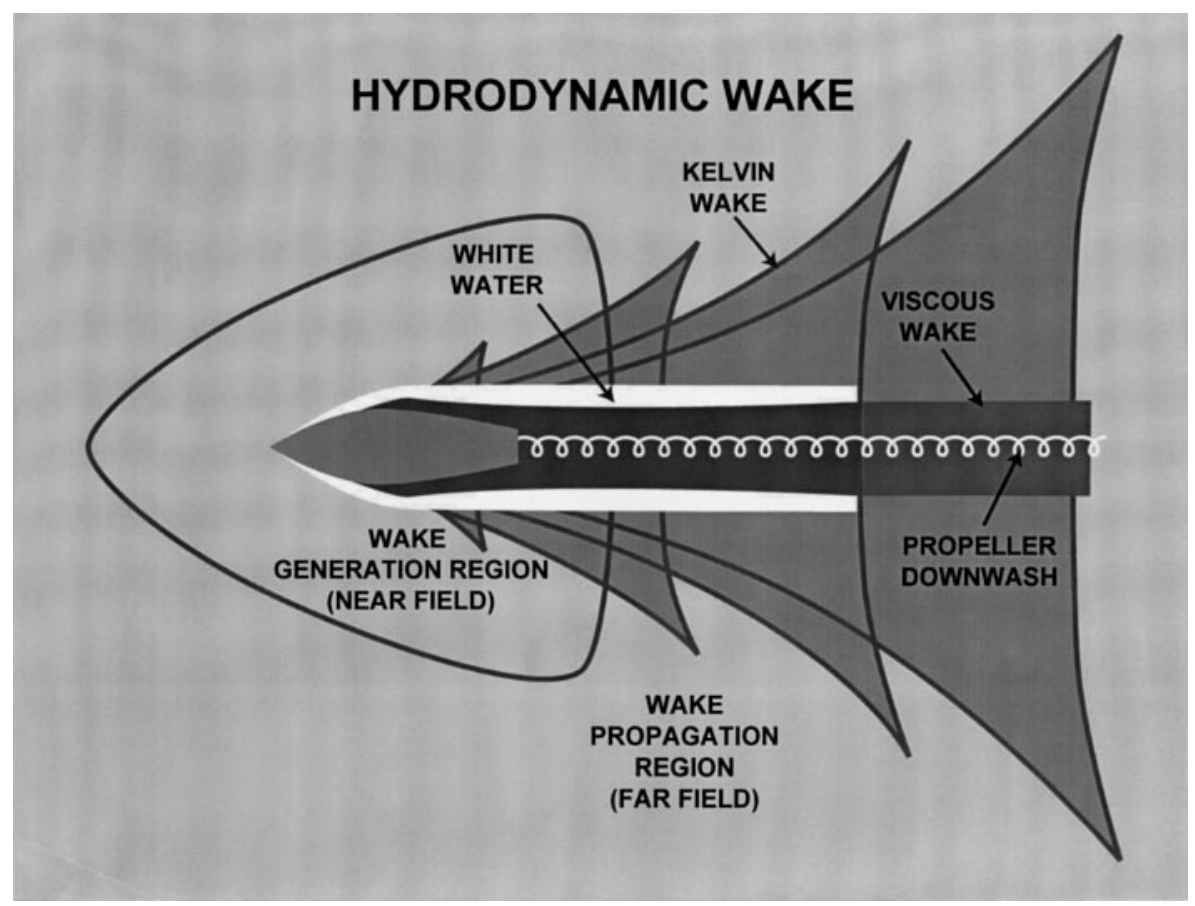

Figure 7 A schematic of a ship wake.

surrounding surface. Turbulent wakes are visible in SAR imagery as a dark narrow line along the ship's track when the surface is sufficiently rough to yield a measurable background return. The background return is suppressed in the region near the ship track by interactions between the momentum wake of the ship and the ambient wave field (Lyden et al. 1988), resulting in the near-ship portion of the "dark centerline return."

It is often useful to draw an imaginary oval, extending several ship beams ahead of and off to each side of the ship and a ship length or so aft of the ship. The region internal to the oval is called the near field, and the region external to the oval is the far field. The near field can be thought of as the region where surface foam, subsurface bubbles, and strong turbulence is generated. It is also where the most rapid decay of these features occurs. Foam is generated by the entrainment of air in the form of small bubbles at and below the surface. There are three major sources of the highly energetic white water in this region. One is the bow wave generated by the ship's motion breaks. The region adjacent to the ship's hull also produces foam, bubbles, and turbulence because of the frictional drag forces at the surface of the hull. The initial spreading region of the viscous and propeller wakes is another region with high angular divergence of foamy, turbulent, white water directly aft of the ship's stern, generally outlined by what appears to be a spilling-type breaking 
wave. In the the distant regions from the ship, the dark centerline in the images is due to attenuation of Bragg-scattering sea waves by surfactant tracks caused by passage of the ship and near-ship breaking waves (Kaiser et al. 1988, Peltzer et al. 1992, Milgram et al. 1993a,b).

In turn, the far field is the region where the variations in the wake are relatively slow. Further downstream, the surface foam and bubbles, and the surface roughness gradually returns to that of the surrounding ambient environment. Highaltitude photographs released by NASA show that the region of smooth water (turbulent wake) can sometimes be observed as far as $100 \mathrm{~km}$ behind a ship (Munk et al. 1987). Various wake features up to $15 \mathrm{~km}$ aft of the ship are visible in SEASAT SAR imagery (Lyden et al. 1988, Vesecky \& Stewart 1982). Under extremely rough conditions, no far-wake region can be observed by any method.

\subsection{Observed Radar Image Morphology}

One of the striking features of the remote observation of surface ship wakes using SAR imagery is the apparent variability of the wake angles. A program of sea trials called JOWIP was conducted jointly by NOSC and DREP to determine the detectability of wakes by SAR ocean wave-pattern imaging (Hammond et al. 1985). Ship-generated waves of known wavelength and direction were observed with an airborne L-band SAR to study, under selected sea conditions, the hydrodynamic contributions to the detectability of the wake. Lyden et al. (1988) analyzed much of the narrow $\mathrm{V}$-wake data from these experiments and concluded that the bright images were produced by ship-generated Bragg waves moving away from the ship track. There were only light winds at the field test site during these experiments.

It has been proposed by Case et al. (1985) that the SAR images of the narrow $\mathrm{V}$-wakes are caused by intermittency or unsteadiness in the divergent waves of the Kelvin wake producing wavelengths in the Bragg scattering range of the radar. This generally is supported by the hypothesis of Lyden et al. (1988). High-resolution photographs of ship wakes taken during a 1985 shuttle mission also were analyzed by Munk et al. (1987). In contrast to the radar images it was concluded that the optical images were due to interference fringes resulting from a complex geometry of sources in the ship wake. Low-wind conditions again prevailed in the vicinity of the wake detection and observation.

For ship waves having wavelengths corresponding to the Bragg scattering wavelength, Milgram (1988) performed a hydrodynamic analysis of the Kelvin-wave system. Qualitatively, he found that the Kelvin wake is capable of producing bright V-wake returns. Hall et al. (1987) have performed a similar hydrodynamic analysis, assuming that the origin of the disturbance is an unsteady source, such as wave breaking, traveling with the ship. This unsteady disturbance produces a wave pattern that is similar to the Kelvin wake generated by a ship undergoing steady forward motion. This corresponds to the model proposed by Case et al. (1985). Hall et al. found that the unsteady, Kelvin wake-like disturbance is also capable 
of producing bright narrow V-wakes. Both steady and unsteady waves made by a moving ship produce divergent waves capable of Bragg scattering radar signals along narrow V-rays.

In 1984, a field study (called SIR-B) was conducted jointly by the Naval Research Laboratory and the David Taylor Model Basin. In the study an L-band SAR was carried into orbit by the space shuttle and was employed to image the wake of several surface vessels. Some images displayed the characteristic bright narrow V-feature, but the dead water region, or centerline wake, was the most prominent overall feature, occurring in all ships' signatures.

An analysis of two SIR-B ship-wake images (which included a total of five ships) was reported by Schurmann (1989). The purpose of the study was to test matched filters based on empirical wake-signature models against the SIR-B images of four ships, two traveling in the radar's range direction and two traveling in the azimuthal direction. The two ships traveling in the azimuthal direction displayed both the dark centerline wake and bright V-arms, whereas the two rangetraveling ships displayed only the dark centerline wake feature. The results of the matched filter study produced optimum signal-to-noise ratios of 17 to $21 \mathrm{~dB}$, which led Schurmann to conclude that wake signatures can be exploited successfully for surface ship detection.

In contrast to the bright V-wake images, which are often observed using SAR, there also is the relatively narrow, dark centerline image along the ship track, which commonly persists for many kilometers downstream. The dark portion of the radar image suggests that this region of the surface is relatively smooth and free of short-wavelength scatterers. This region has been described as the turbulent wake or scar of the ship, but computations by Swean (1987) to simulate the wake of a twin-screw, high-speed destroyer from model test data suggest strongly that the surface features of the classical turbulent ship wake do not persist sufficiently far downstream to explain the SAR images. As described previously, damping of short radar-scattering sea waves by turbulence can contribute to the dark centerline radar return near the ship, but wave damping by redistributed surfactants is the dominant source of the dark centerline many ship lengths aft of the ship.

\section{KELVIN WAKES}

Sir William Thompson (1887a), later Lord Kelvin, first provided a mathematical description of the wave pattern that now bears his name. This pattern is illustrated in Figures 1, 6, and 7. The Kelvin-wave pattern for a point disturbance has been analyzed from two distinct directions: by means of wave kinematics and by analysis of the Green function. We provide a brief history of the development of the Kelvinwave pattern and provide a mathematical description of the Kelvin-wave pattern based on wave kinematics.

As just stated, Kelvin provided the first mathematical description of the shipwave pattern. His development was based on wave kinematics; to perform this 
analysis, Kelvin developed the method of stationary phase. Numerous other workers have followed and refined Kelvin's kinematic analysis; these include Havelock (1908, 1934; also see Wigley 1965, pp. 1-3, 377-89), Lamb (1945), Stoker (1957), Newman (1977), and Yih \& Zhu (1989a,b).

Newman provides a particularly cogent derivation of the Kelvin wave pattern. He starts with a simple kinematical development, and then identifies the wave pattern using two approaches: He first provides a heuristic derivation. He then backs it up with a rigorous analysis using the method of stationary phase. In deriving the Kelvin-wave pattern, he finds the relation between the direction of wave propagation $\theta$ at a point in the wave pattern and the polar angle $\alpha$ providing the coordinate of the point, such that

$$
\tan \theta=\frac{1 \pm \sqrt{1-8 \tan ^{2} \alpha}}{4 \tan \alpha} .
$$

The relation between $\alpha$ and $\theta$, Equation 1, is plotted in Figure 8. The maximum value of $\alpha$ for which Equation 1 can be solved for $\theta$ is $\tan \alpha=1 / 2 \sqrt{2}$, or $\alpha=19^{\circ} 28^{\prime}$. The corresponding value of $\theta$ is $\tan \theta=1 / \sqrt{2}$, or $\theta=35^{\circ} 16^{\prime}$. As can be seen from Equation 1 and Figure 8, for values of $\alpha$ less than $19^{\circ} 28^{\prime}$, there are two values of $\theta$, one less than $35^{\circ} 16^{\prime}$ and the other greater. The waves for which $\theta$ is less than $35^{\circ} 16^{\prime}$ are called the transverse waves, whereas those for which $\theta$ is greater than $35^{\circ} 16^{\prime}$ are known as the diverging waves.

The asymptotic equation for the Kelvin-wave pattern $Z(x, y)$, valid for large $g r / U^{2}$, is

$$
Z(R, \alpha)=\Re A\left(\theta_{0}\right)\left\{\frac{2 \pi U^{2}}{g r\left|f^{\prime \prime}\left(\theta_{0}\right)\right|}\right\}^{1 / 2} e^{-i \frac{g r}{U^{2}}\left(\frac{\sin \alpha \sin \theta_{0}-\cos \alpha \cos \theta_{0}}{\cos ^{2} \theta_{0}}\right) \pm i \frac{\pi}{4}},
$$

where $A(\theta)$ is the free-wave spectrum (Eggers et al. 1967, Wehausen 1973), $U$ is the speed of the disturbance, $r\left(=\sqrt{x^{2}+y^{2}}\right)$ is the two-dimensional distance

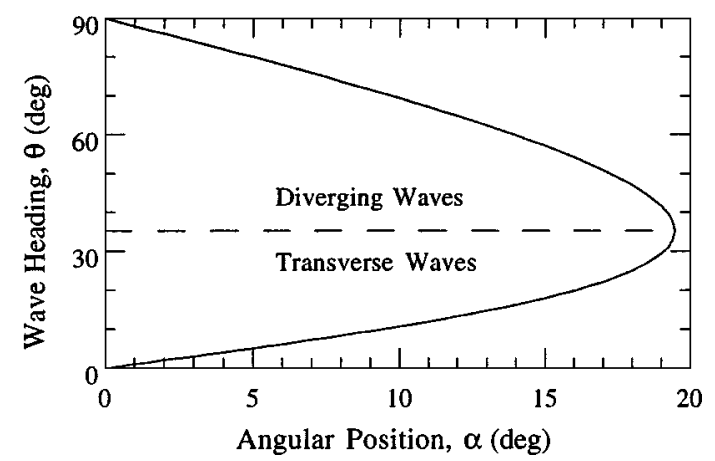

Figure 8 Wave heading, $\theta$, versus angular position, $\alpha$, for waves in the Kelvin-wave pattern. 
from the disturbance to the field point on the free surface, $f(\theta)=(\sin \alpha \sin \theta-$ $\cos \alpha \cos \theta) / \cos ^{2} \theta$, and $\theta_{0}$ is the value of $\theta$ corresponding to $\alpha$ [according to (Equation 1)]. The sign on the $\pi / 4$ phase angle term in the exponential corresponds to the sign of $f^{\prime \prime}\left(\theta_{0}\right)$ in the denominator of the magnitude term. The sign of $f^{\prime \prime}$ changes as the waves transition from transverse waves to diverging waves. Thus at the cuspline, the phases of the transverse and diverging waves differ by $\pi / 2$.

On the $19^{\circ} 28^{\prime}$ cuspline, $f^{\prime \prime}$ is identically zero, so that yet another form of the asymptotic expansion must be employed. This form of the asymptotic expansion gives $Z(R, \alpha)$ as

$$
Z(R, \alpha)=\Re \Gamma\left(\frac{4}{3}\right) A\left(\theta_{0}\right)\left\{\frac{6 U^{2}}{g r\left|f^{\prime \prime \prime}\left(\theta_{0}\right)\right|}\right\}^{1 / 3} e^{-i \frac{g r}{U^{2}}\left(\frac{\sin \alpha \sin \theta_{0}-\cos \alpha \cos \theta_{0}}{\cos ^{2} \theta_{0}}\right) \pm i \frac{\pi}{6}}
$$

Thus on the cuspline the wave amplitude decays much more slowly than in the interior. This result was first reported by Havelock (1908; see also Wigley 1965, pp. 1-3). The behavior along the cuspline has been extensively studied by Hogner (1923), Peters (1949), and Ursell (1960).

Yih \& Zhu (1989a,b) have developed an elegant analysis for predicting the wave pattern generated by a disturbance given only the dispersion relation. Their analysis makes use of three fundamental relationships, the stationary phase relationship, the fact that constant phase lines are perpendicular to the wave-number vector, and the fact that the local phase velocity must be equal to the component of the steady disturbance velocity in the direction of the wave-number vector. Using only these wave kinematics, they have developed an extensive set of wave patterns covering a variety of conditions. These patterns cover infinite depth, finite depth, stratified fluids, capillary waves on thin sheets, infinite depth with nonuniformities in the onset flow as would be seen in the viscous wake of a ship, and cases with surface tension so that both gravity and capillary waves are present.

\subsection{Full Kelvin-Wake Boundary Value Problem}

The boundary value problem for the Kelvin wake of a ship moving with steady forward speed on an otherwise undisturbed free surface constitutes a problem that is extremely difficult to solve. Even with the assumptions that the flow is irrotational and that the fluid is incompressible and inviscid so that our problem can be treated as a potential flow problem governed by the Laplace equation, the problem remains extremely difficult. This is a result of "a pair of wickedly nonlinear boundary conditions on the (unknown) free surface of the water" (Tuck 1990). As a result of these nonlinear free-surface boundary conditions, various linearization schemes have been developed that allow the solution of various approximations to the wave-making problem. In this section, we derive the fully nonlinear Kelvin-wake problem and discuss the various linearizations that are employed to derive approximate solutions to the Kelvin-wake problem. 
FIELD EQUATIONS The viscous flow around a ship is governed by the NavierStokes and continuity equations:

$$
\begin{gathered}
\frac{\partial u_{i}}{\partial t}+u_{j} \frac{\partial u_{i}}{\partial x_{j}}=-\frac{\partial p}{\partial x_{i}}+\rho g_{i}+v \nabla^{2} u_{i} \\
\frac{\partial u_{i}}{\partial x_{i}}=0
\end{gathered}
$$

where the $u_{i}, i=1,2,3$ are the $x-, y$-, and $z$-components of the velocity, $p$ is the pressure, $g_{i}$ is the component of the gravitational acceleration $\mathbf{g}$ in the $x_{i}$-direction, and double subscripts within a term imply summation over that index.

Equations 4 and 5 apply to any viscous flow, laminar, or turbulent. As we are interested in the flow around ships with forward speed, the flow will be turbulent over substantially all of the ship's surface. Thus, the velocity $u_{i}$ must account for the total velocity including the time-dependent turbulent velocity components with fast variation, both temporal and spatial. This results in a computationally intractable problem for fluid volumes the size of a ship on the ocean's surface.

The commonly accepted way in which this problem is made tractable is to decompose the velocities and pressures into slowly varying and rapidly varying components. Doing this, one obtains $u_{i}=\bar{u}_{i}+u_{i}^{\prime}$ and $p=\bar{p}+p^{\prime}$, where the "overbar" represents a Reynolds average taken over a time/spatial scale that is large relative to the scale of the turbulence and the primed quantities account for the velocities and pressure at turbulent scales. Substituting this decomposition of the velocity and pressure into Equations 4 and 5, one obtains the Reynolds-averaged Navier-Stokes (RANS) and continuity equations:

$$
\begin{gathered}
\frac{\partial \bar{u}_{i}}{\partial t}+\bar{u}_{j} \frac{\partial \bar{u}_{i}}{\partial x_{j}}=-\frac{\partial \bar{p}}{\partial x_{i}}+\rho g_{i}+v \nabla^{2} \bar{u}_{i}-\frac{\partial \tau_{i j}}{\partial x_{j}} \\
\frac{\partial \bar{u}_{i}}{\partial x_{i}}=0,
\end{gathered}
$$

where $\tau_{i j}=\overline{u_{i} u_{j}}$ is the Reynolds stress tensor.

Equations 6 and 7 constitute four equations for 13 unknowns: the three velocities, the pressure, and the nine components of the Reynolds stress tensor. Thus, the equations are not closed. To obtain closure, the Reynolds stress tensor is usually related to the mean velocities by an eddy viscosity. This generally involves the introduction of another variable such as the turbulent kinetic energy and an equation relating the turbulent kinetic energy to the mean velocities and the eddy viscosity. Speziale (1992) provides a survey of Reynolds stress models.

The classical methods for solving the wave-making problem and predicting the Kelvin wake is to neglect viscosity and assume that the flow is irrotational, resulting in a potential flow whose flow field can be represented by a velocity potential, $\Phi(x, y, z)$, which must satisfy the continuity equation. The partial differential equation that satisfies the continuity equation is the Laplace equation throughout 
the fluid domain:

$$
\nabla^{2} \Phi=\Phi_{x x}+\Phi_{y y}+\Phi_{z z}=0
$$

where the potential is related to the fluid velocity vector $\mathbf{V}$ by $\mathbf{V}=\nabla \Phi$.

BODY BOUNDARY CONDITION For a viscous flow both a kinematic and a "no-slip" condition exist on the hull surface. The kinematic boundary condition of no flow through the surface of the hull is $\mathbf{V} \cdot \mathbf{n}=0$, where $\mathbf{n}$ is the normal to the ship's wetted surface. The no-slip viscous boundary condition has the tangential velocity on the hull as $\mathbf{V} \cdot \mathbf{t}=0$, where $\mathbf{t}$ is a vector tangent to the hull surface.

In the case of an inviscid flow, there is only one boundary condition on the surface of the ship, the kinematic body boundary condition:

$$
\mathbf{V} \cdot \mathbf{n}=\nabla \Phi \cdot \mathbf{n}=\frac{\partial \Phi}{\partial n}=0, \quad \text { on } S(x, z)-y=0
$$

where $\partial / \partial n$ denotes the derivative in the direction of the normal vector pointing into the body and $S(x, z)$ represents the surface of the ship.

FREE SURFACE BOUNDARY CONDITION On the free surface, there is a kinematic condition of no fluid flow through the surface, a dynamic condition that requires that the pressure equal the atmospheric pressure and, neglecting forces from the air, that there be a no-shear condition. The no-shear condition on the free surface does not mean that there are no viscous effects at the free surface. Owing to the nature of wave flow, there is an inherent natural shear, which, even for small-amplitude linear waves, results in a thin viscous layer near the free surface (cf. Mei 1983). The gradients due to the wave motion are small compared to the gradients near the hull where the no-slip condition is applied. If one is only interested in the body forces and the flow local to the ship, the gradients in the waves may be neglected with no significant consequences. However, in SAR imaging of the Kelvin wake far from a ship, the free-surface boundary layer could be significant-even though there is no extant capability to predict the viscous free-surface shear layer far from the ship.

In inviscid flow, only two free-surface boundary conditions apply: the dynamic free-surface condition and the kinematic free-surface condition,

$$
\begin{gathered}
g Z+\frac{1}{2} \nabla \Phi \cdot \nabla \Phi=\frac{1}{2} U^{2}, \quad \text { on } z=Z(x, y), \\
\Phi_{x} Z_{x}+\Phi_{y} Z_{y}-\Phi_{z}=0, \quad \text { on } z=Z(x, y),
\end{gathered}
$$

where $g$ is the acceleration due to gravity and $Z$ is the free-surface elevation. Finally, we must have a radiation condition that requires that the disturbance created by the body vanish at points infinitely far away and that the far-field free-surface waves generated by the body not radiate upstream of the ship. Equations 10 and 11 can 
be combined to give

$$
\frac{1}{2}(\nabla \Phi \cdot \nabla \Phi)_{x} \Phi_{x}+\frac{1}{2}(\nabla \Phi \cdot \nabla \Phi)_{y} \Phi_{y}+g \Phi_{z}=0, \quad \text { on } z=Z(x, y) .
$$

Let us now write the potential, $\Phi$, as the sum of two potentials, that of some basis flow, $\phi$, and a perturbation potential, $\varphi$,

$$
\Phi=\phi+\varphi \text {. }
$$

The potentials of both the basis flow and the perturbation flow are solutions to the Laplace equation. The basis flow is chosen as the solution to some simpler problem whose free-surface boundary condition is simple. In general, the basis flow will satisfy the radiation condition in a trivial manner. It will be assumed that the perturbation potential is in some sense small relative to the basis flow potential. However, depending on the basis flow that is chosen, neither the basis flow nor the perturbation potential may satisfy the body boundary condition separately.

If we now substitute the basis-flow/perturbation-flow expansion (Equation 13) into the nonlinear free-surface boundary condition, Equation 12, we obtain the following expansion of the nonlinear free-surface boundary condition

$$
\begin{aligned}
& \frac{1}{2}(\nabla \phi \cdot \nabla \phi+2 \nabla \phi \cdot \nabla \varphi+\nabla \varphi \cdot \nabla \varphi)_{x}\left(\phi_{x}+\varphi_{x}\right)+\frac{1}{2}(\nabla \phi \cdot \nabla \phi+2 \nabla \phi \cdot \nabla \varphi \\
& \quad+\nabla \varphi \cdot \nabla \varphi)_{y}\left(\phi_{y}+\varphi_{y}\right)+g\left(\phi_{z}+\varphi_{z}\right)=0, \quad \text { on } z=Z(x, y) .
\end{aligned}
$$

This is the final form of the exact nonlinear free-surface boundary condition.

In most of the work that follows, we discuss various linearized forms of the free-surface boundary condition. To perform our linearization of Equation 14, we first neglect all terms that are second order and higher in the perturbation potential, $\varphi$, which results in

$$
\begin{aligned}
& \frac{1}{2}(\nabla \phi \cdot \nabla \phi)_{x} \phi_{x}+\frac{1}{2}(\nabla \phi \cdot \nabla \phi)_{x} \varphi_{x}+(\nabla \phi \cdot \nabla \varphi)_{x} \phi_{x}+\frac{1}{2}(\nabla \phi \cdot \nabla \phi)_{y} \phi_{y} \\
& \quad+\frac{1}{2}(\nabla \phi \cdot \nabla \phi)_{y} \varphi_{y}+(\nabla \phi \cdot \nabla \varphi)_{y} \phi_{y}+g\left(\phi_{z}+\varphi_{z}\right)=0, \quad \text { on } z=Z(x, y) .
\end{aligned}
$$

To complete our linearization, we then expand the potentials of Equation 15 in a one-term Taylor series around the undisturbed free surface $z=0$. To accomplish this, we need an equation for the free-surface elevation. We obtain this by rewriting Equation 10 in terms of the basis-flow/perturbation-flow expansion, Equation 13. Upon linearization, this yields

$$
Z=\frac{1}{2 g}\left\{U^{2}-\nabla \phi \cdot \nabla \phi-2 \nabla \phi \cdot \nabla \varphi\right\}=Z_{0}-\frac{1}{g}\{\nabla \phi \cdot \nabla \varphi\}, \quad \text { on } z=0,
$$

where $Z_{0}=\left\{U^{2}-\nabla \phi \cdot \nabla \phi\right\} / 2 g$ is the basis-flow wave elevation. Performing the 
Taylor series expansion and again discarding the second-order and higher terms in the perturbation potential yields

$$
\begin{gathered}
\frac{1}{2}(\nabla \phi \cdot \nabla \phi)_{x} \phi_{x}+\frac{1}{2}(\nabla \phi \cdot \nabla \phi)_{x} \varphi_{x}+(\nabla \phi \cdot \nabla \varphi)_{x} \phi_{x} \\
+\frac{1}{4 g}\left\{(\nabla \phi \cdot \nabla \phi)_{x z} \phi_{x}+(\nabla \phi \cdot \nabla \phi)_{x z} \varphi_{x}+2(\nabla \phi \cdot \nabla \varphi)_{x z} \phi_{x}+(\nabla \phi \cdot \nabla \phi)_{x} \phi_{x z}\right. \\
\left.+(\nabla \phi \cdot \nabla \phi)_{x} \varphi_{x z}+2(\nabla \phi \cdot \nabla \varphi)_{x} \phi_{x z}\right\}\left(U^{2}-\nabla \phi \cdot \nabla \phi\right) \\
-\frac{1}{2 g}\left\{(\nabla \phi \cdot \nabla \phi)_{x z} \phi_{x}+(\nabla \phi \cdot \nabla \phi)_{x} \phi_{x z}\right\} \nabla \phi \cdot \nabla \varphi \\
+\frac{1}{2}(\nabla \phi \cdot \nabla \phi)_{y} \phi_{y}+\frac{1}{2}(\nabla \phi \cdot \nabla \phi)_{y} \varphi_{y}+(\nabla \phi \cdot \nabla \varphi)_{y} \phi_{y} \\
+\frac{1}{4 g}\left\{(\nabla \phi \cdot \nabla \phi)_{y z} \phi_{y}+(\nabla \phi \cdot \nabla \phi)_{y z} \varphi_{y}+2(\nabla \phi \cdot \nabla \varphi)_{y z} \phi_{y}+(\nabla \phi \cdot \nabla \phi)_{y} \phi_{y z}\right. \\
\left.+(\nabla \phi \cdot \nabla \phi)_{y} \varphi_{y z}+2(\nabla \phi \cdot \nabla \varphi)_{y} \phi_{y z}\right\}\left(U^{2}-\nabla \phi \cdot \nabla \phi\right) \\
-\frac{1}{2 g}\left\{(\nabla \phi \cdot \nabla \phi)_{y z} \phi_{y}+(\nabla \phi \cdot \nabla \phi)_{y} \phi_{y z}\right\} \nabla \phi \cdot \nabla \varphi \\
+g\left(\phi_{z}+\varphi_{z}\right)+\frac{1}{2}\left(\phi_{z z}+\varphi_{z z}\right)\left(U^{2}-\nabla \phi \cdot \nabla \phi\right)-\phi_{z z} \nabla \phi \cdot \nabla \varphi=0, \quad \text { on } z=0 .
\end{gathered}
$$

In Equation 17, we have been consistent in our expansion of the free-surface boundary condition around $z=0$. Lines $17 \mathrm{a}$ and $17 \mathrm{~d}$, and the first term on line $17 \mathrm{~g}$ are directly from Equation 16, but they are now evaluated on $z=0$ rather than on $z=Z(x, y)$. The terms from lines $17 \mathrm{~b}$ and $17 \mathrm{e}$, and the second term in line $17 \mathrm{~g}$ are a result of differentiating with respect to $z$ and multiplying by the basis flow wave elevation, $Z_{0}(x, y)$. Finally, the terms on lines $17 \mathrm{c}$ and $17 \mathrm{f}$, and the third term of line $17 \mathrm{~g}$ are a result of differentiating with respect to $z$ and multiplying by the perturbation-flow contribution to the wave elevation. There are many more terms in lines $17 \mathrm{~b}$ and $17 \mathrm{e}$ than in lines $17 \mathrm{c}$ and $17 \mathrm{f}$, due to the fact that the perturbation flow contribution to the wave elevation can only multiply terms containing just the basis flow.

In the process of linearizing the free-surface condition, many authors assume that the perturbation-flow contribution to the wave elevation is higher order than the perturbation flow and, in fact, neglect these terms. Many authors also assume that the basis-flow wave elevation is also of higher order than the basis flow. Because of these assumptions, the terms on lines 17b, 17c, 17e, and 17f, and the second and third terms of line $17 \mathrm{~g}$ are neglected by most authors performing this linearization. However, it is necessary to keep some of these terms or there is no wave excitation of the perturbation flow by the basis flow. Lastly, the perturbation potential must satisfy a radiation condition that requires that the disturbance vanish at points infinitely far away and that the waves not radiate upstream of the ship. 
The traditional basis flow for use in setting up ship free-surface flows has been the free-stream flow $-U x$. That is to say $\phi(x, y, z)=-U x$. Substituting this basis-flow potential into Equation 16, and discarding all terms that are identically zero yields the following linearized free-surface boundary condition:

$$
\varphi_{x x}+k_{0} \varphi_{z}=0, \quad \text { on } z=0,
$$

where $k_{0}=g / U^{2}$. The radiation condition for this problem remains unchanged. This is the free-surface boundary condition for the Neumann-Kelvin problem.

DAWSON'S FREE-SURFACE BOUNDARY CONDITION The Dawson methods are named after Charles Dawson (1977) who first formulated the method. In Dawson's approach to the Kelvin-wake problem, the basis flow is the double-body potential. The double-body potential corresponds to the limiting solution as the Froude number goes to zero (i.e., $g \gg U$ ), for which case the free surface acts as a rigid wall. The double-body potential is a solution to the Laplace equation (Equation 8) at all points outside of the body. It satisfies the exact hull boundary condition (Equation 9) and a rigid wall boundary condition applied on the position of the undisturbed free surface: $\phi_{z}=0$, on $z=0$. The double-body solution can be readily obtained by boundary-element methods utilizing Rankine $(1 / R)$ singularities, and it is assumed throughout the remainder of this discussion that the double-body potential and its derivatives can be treated as known quantities.

The perturbation potential must be a solution to the Laplace equation throughout the fluid domain and must satisfy the hull boundary condition. By defining a wave elevation $Z_{0}$ that depends only on the double-body potential and assuming that the wave elevation $Z(x, y)$ is composed of $Z_{0}$ plus additional terms that are of the order $\varphi$, we can obtain the linearized boundary condition to be satisfied on the undisturbed free surface,

$$
\begin{gathered}
\frac{1}{2}(\nabla \phi \cdot \nabla \phi)_{x} \phi_{x}+\frac{1}{2}(\nabla \phi \cdot \nabla \phi)_{x} \varphi_{x}+(\nabla \phi \cdot \nabla \varphi)_{x} \phi_{x}+\frac{1}{4 g}\left\{(\nabla \phi \cdot \nabla \phi)_{x z} \phi_{x}\right. \\
\left.+(\nabla \phi \cdot \nabla \phi)_{x z} \varphi_{x}+2(\nabla \phi \cdot \nabla \varphi)_{x z} \phi_{x}\right\} Z_{0}-\frac{1}{2 g}\left\{(\nabla \phi \cdot \nabla \phi)_{x z} \phi_{x}\right\} \nabla \phi \cdot \nabla \varphi \\
+\frac{1}{2}(\nabla \phi \cdot \nabla \phi)_{y} \phi_{y}+\frac{1}{2}(\nabla \phi \cdot \nabla \phi)_{y} \varphi_{y}+(\nabla \phi \cdot \nabla \varphi)_{y} \phi_{y}+\frac{1}{4 g}\left\{(\nabla \phi \cdot \nabla \phi)_{y z} \phi_{y}\right. \\
\left.+(\nabla \phi \cdot \nabla \phi)_{y z} \varphi_{y}+2(\nabla \phi \cdot \nabla \varphi)_{y z} \phi_{y}\right\} Z_{0}-\frac{1}{2 g}\left\{(\nabla \phi \cdot \nabla \phi)_{y z} \phi_{y}\right\} \nabla \phi \cdot \nabla \varphi \\
+g \varphi_{z}+\frac{1}{2}\left(\phi_{z z}+\varphi_{z z}\right) Z_{0}-\phi_{z z} \nabla \phi \cdot \nabla \varphi=0, \quad \text { on } \mathrm{z}=0 .
\end{gathered}
$$

Because the double-body potential tends to the free-stream potential as we move away from the body, in the far field, the Dawson free-surface boundary condition approaches the linear, Kelvin, free-surface boundary condition, Equation 18. 
Consequently, the differences between the Dawson solution and the NeumannKelvin solution must be due to the differences between their respective free-surface boundary conditions, Equations 18 and 19, which occur in a relatively limited region around the hull.

\subsection{Numerical Modeling}

Solutions of the RANS equations require that the entire computational fluid domain be gridded and that the field equations be solved by finite element or finite difference methods. Usually potential-flow problems are solved by boundary element methods, with the boundary elements distributed over the body surface and often the free surface.

The boundary element methods employ either simple Rankine singularities that only satisfy the Laplace equation, Equation 13, or Havelock singularities that satisfy both the Laplace equation and the linearized free-surface boundary condition, Equation 18. The potential of the Rankine singularity is given by $1 / R$, where $R=\left[\left(x-x^{\prime}\right)^{2}+\left(y-y^{\prime}\right)^{2}+\left(z-z^{\prime}\right)^{2}\right]^{1 / 2}$ is the distance between the field point and the singularity point. Because they do not satisfy the free-surface boundary condition, Rankine singularities must be distributed over both the surface of the hull and the free surface.

Havelock singularities are generally distributed only over the surface of the hull, although they can also be distributed on the free surface. A form of the HavelockGreen function is given by Wehausen \& Laitone (1960). It consists of two Rankine singularity terms, a double integral and a single integral. The double integral term requires the evaluation of two highly oscillatory integrals. As a consequence of the radiation boundary condition, upstream of the singularity, the double integral cancels the waves from the single integral term. Downstream of the singularity, the double integral adds to the single integral resulting in far-field waves, which decay like $1 / \sqrt{R}$ downstream of the singularity. Much effort has been expended in developing efficient methods for evaluating the double integral.

The single and double integrals can be manipulated by means of changes of variables, by contour integration, and by the addition and subtraction of $1 / R$ and its Fourier integral representation, to obtain many other forms of the Green function (Noblesse 1981, Newman 1987a,b) that are more amenable to analysis.

Solution methods that do not employ Havelock singularities are, as a consequence of the requirement that the fluid volume and/or the free surface be gridded, restricted to predicting the wave field quite near the ship. To predict the wave field many ship lengths astern, the asymptotic representation of the wave spectral representation, Equations 2 and 3, must be employed to extrapolate the solution near the ship into the far field. The easiest means of doing this is to perform a transverse wave cut (cf. Eggers et al. 1967) to obtain a wave spectrum $(A(\theta))$ that can be used to predict waves far from the ship. The major deficiency of this approach is the lack of wave breaking in the predictions near the ship that serves to reduce the amplitude of waves far from the ship. 
STEADY RANS CODES Four free-surface RANS codes that can solve the steady-ship wave problem are DTNS3D (Haussling et al. 1997), the Princeton code (Cowles \& Martinelli 1998), CFDSHIP-IOWA (Wilson et al. 1998), and UNCLE (Arabshahi et al. 1998). As stated above, these codes solve the field equations using a finite volume or finite difference scheme. All of the codes employ a multiblock approach to the grid. They obtain a stable converged solution by iterating in time until a steady state is reached. Both CFDSHIP-IOWA version 3.2 and UNCLE are capable of solving the RANS equations in either time-accurate or steady-flow modes.

Each of the codes satisfies the full nonlinear free-surface boundary condition by employing some type of upstream differencing scheme on the free surface. The fact that the fluid volume must be regridded to track the nonlinear free-surface deformation adds a significant complication to the iteration scheme and adds significantly to the computation time. Solutions using nonlinear free-surface RANS codes such as these can take $40-80 \mathrm{~h}$ or more to compute on a state-of-the-art multiprocessor super computer.

Figure 9 shows the model-scale wave contours measured using stereo photography on David Taylor Model Basin (DTMB) Model 5415, a model representative of a contemporary transom stern combatant hull form (for complete details of this transom stern hull form along with many experimental and computational results, see http://www50.navy.mil/5415) at a Froude number of 0.2755 . Figure 10 provides the wave contours predicted by the RANS code UNCLE for the same Froude number. The fidelity of the predictions is quite good except outboard of the hull at the stern, where grid resolution limitations result in a loss of accuracy.

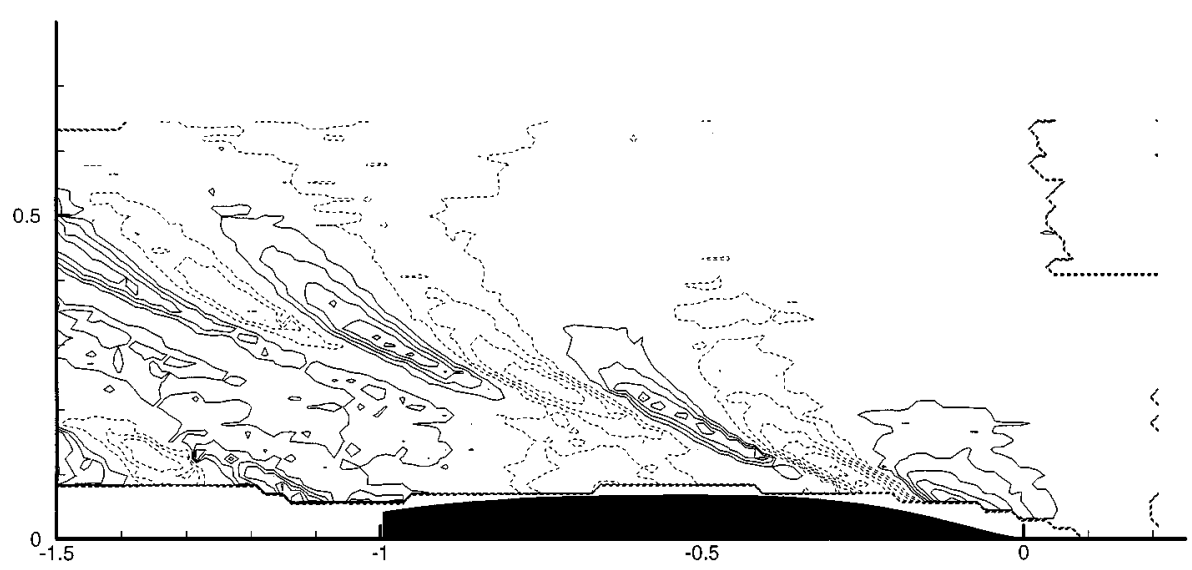

Figure 9 Measured wave contours for DTMB Model 5415 at a Froude number of 0.2755. Wave crests are solid lines drawn for contour levels of $0.002 L, 0.004 L, \ldots, 0.02 L$. Dashed lines represent wave troughs at contour levels of $-0.002 L,-0.004 L, \ldots,-0.02 L$. (courtesy of John Telste) 


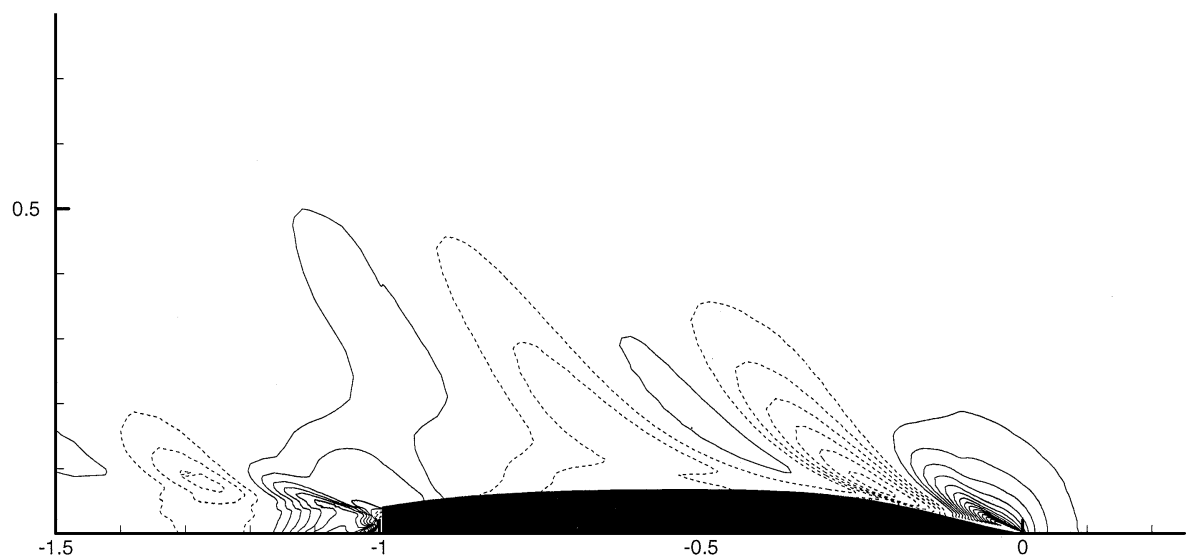

Figure 10 Wave contours predicted using the RANS code UNCLE for DTMB Model 5415 at a Froude number of 0.2755 . Wave crests are solid lines drawn for contour levels of $0.002 L, 0.004 L, \ldots, 0.02 L$. Dashed lines represent wave troughs at contour levels of $-0.002 L,-0.004 L, \ldots,-0.02 L$. (courtesy of Joseph Gorski \& John Telste).

Other experimental data show quite good agreement between the measured data and UNCLE predictions immediately aft of the transom.

NONLINEAR POTENTIAL FLOW RAPID (Raven 1996, 1998), UMDELTA (Scorpio 1997, Subramani 2000), and DAS BOOT (Wyatt 2000) are nonlinear potential flow methods for predicting the wave field around ships. All three codes employ Rankine singularities and desingularize the free surface. ${ }^{1}$ However, downstream of the ship, DAS BOOT does transition to Havelock singularities on the undisturbed free surface. RAPID and DAS BOOT treat the ship's hull using a traditional boundary element approach, whereas UMDELTA uses the desingularized approach to represent the hull.

All three codes solve the boundary value problem iteratively. UMDELTA is actually a time-dependent code that can accelerate the ship from zero speed to a constant speed. Whereas the other two codes iterate in "time" to obtain a converged stable free-surface elevation prediction. Both RAPID and UMDELTA employ an iterative solver to obtain the solution at each time step. They both require that the linear system of equations be preconditioned to obtain reasonable convergence rates.

NEUMANN-KELVIN PROBLEM This common formulation of the ship-wave problem reduces the problem to the solution of an integral equation on the body

\footnotetext{
${ }^{1}$ By desingularization, we mean that the singularities are not placed on the free surface, but rather at some distance above the free surface.
} 
surface by using a Green function that satisfies explicitly the Laplace equation (Equation 13) and the linearized free-surface condition (Equation 18). This boundary value problem is solved by using Green's theorem applied to the surface of the ship, the free surface, and the extremes of the domain at infinity and then solving for the potential (Wehausen 1963, Newman 1977), or by using source-sink distributions on the hull (Hess \& Smith 1964). Doctors \& Beck (1987a,b) and Scragg (Reed et al. 1990b) have developed Havelock-Green function-based methods for computing the solution of the Kelvin-wake problem. Doctors \& Beck and Scragg solve the full Neumann-Kelvin problem for the strengths of the singularities. This results in a body boundary condition that is satisfied exactly.

RANKINE-FS, developed by Telste (Reed et al. 1990b, Telste \& Reed 1993) employs Rankine singularities to solve the Neumann-Kelvin problem, which necessitates distributing Rankine singularities on the free surface as well as on the hull surface.

DAWSON METHODS Dawson methods solve for the Kelvin wake in a two-stage process. The first step involves the solution of a double-body problem where the ship's hull is reflected in the free surface and the flow is predicted as though the body and its reflected image are submerged infinitely deep in the fluid. The second stage of the solution involves solving a free-surface problem that is linearized around the double-body solution. This second solution involves singularities on the free surface as well as on the body. In order to satisfy the free-surface condition, a finitedifference operator is applied in the streamwise direction to satisfy the Dawson free-surface boundary condition (Equation 19). This contrasts with the HavelockGreen function methods that distribute singularities only on the surface of the body. Compared to the Havelock Green function-based methods, the Dawson methods trade a much simpler Green function for a much larger computational domain with many more unknowns.

Cheng (1989), Kim et al. (1989), and Sclavounos \& Nakos $(1988,1990)$ have developed Dawson methods for solving the Kelvin-wake problem using Rankine sources. Cheng's implementation is a direct extension of the original method developed by Dawson. Figure 11 presents a Dawson method calculation using SWAN (Sclavounos \& Nakos 1988, 1990) of the wave pattern around DTMB Model 5415 for the same conditions as those in Figures 9 and 10. Except for aft of the transom, the predictions agree quite well with the experimental results. Other experimental results show that quite significant discrepancies exist immediately behind the transom. These are probably the result of viscous effects that one cannot expect to represent with a potential flow prediction.

Scragg \& Talcott (1990) and Scragg (1999) have developed a "HavelockDawson" approach that employes Rankine singularities on the hull and Havelock singularities on the free surface in a limited region of the undisturbed free surface near the body. The method allows one to "get away" with paneling only a limited region of the free surface because the singularities satisfy both the linearized free-surface and the radiation boundary conditions, resulting in a "self-limiting" 


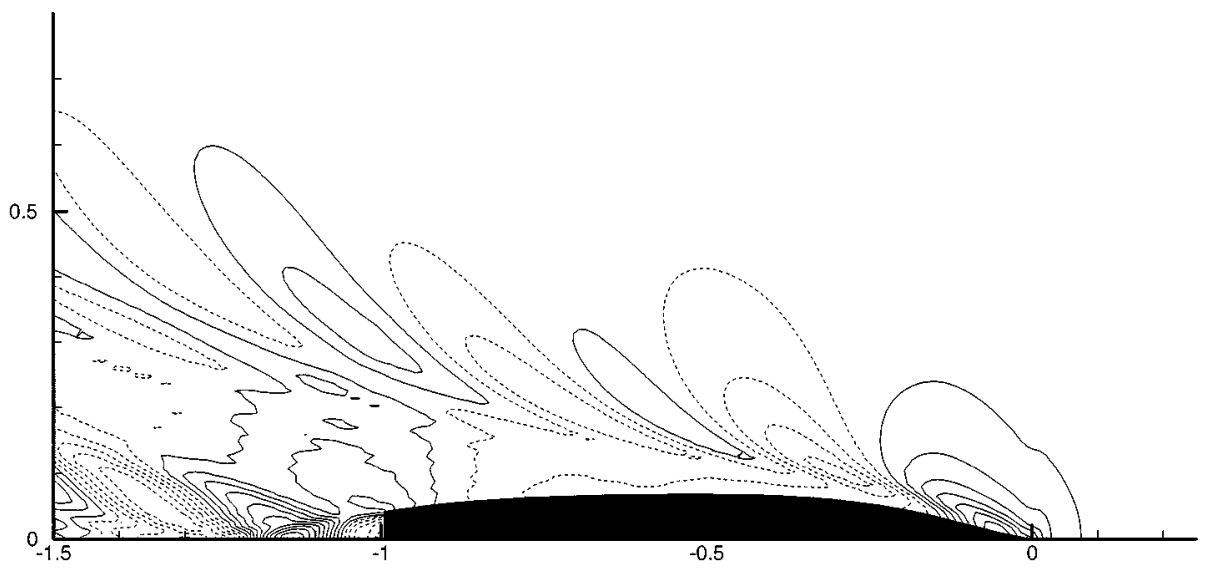

Figure 11 Wave contours predicted using SWAN (Sclavounos \& Nakos 1988, 1990) for DTMB Model 5415 at a Froude number of 0.2755 . Wave crests are solid lines drawn for contour levels of $0.002 L, 0.004 L, \ldots, 0.02 L$. Dashed lines represent wave troughs at contour levels of $-0.002 L,-0.004 L, \ldots,-0.02 L$. (courtesy of John Telste)

distribution of singularities on the free surface. The Havelock-Dawson approach is computationally very efficient. On the hull and from the hull to the free surface, the Rankine singularity influence functions are evaluated very efficiently. On the free surface, the panel-to-panel influence functions are known constants like $4 \pi$. Thus the free surface to body influence-function computations, which make up a relatively small number of evaluations, are the only ones that involve the Havelock-Green function.

\section{CENTERLINE WAKES}

\subsection{Phenomena That Influence Centerline Wakes and the Energy Balance Equation}

A centerline wake is a track behind a ship where short sea waves are attenuated, leaving a surface that is relatively smooth, and has a width that is typically two to three times the ship beam. If there is a violently bubbly and turbulent zone behind the ship, which may include breaking waves locally generated by the ship and whose length typically approximates two ship beams, the smooth region begins just aft of this zone and its length will depend on many factors, including the state of the surrounding sea. In light to moderate winds and sea states, centerline wakes can be tens of kilometers long. The phenomena that influence both the calmness of the centerline wake and the regrowth of the waves to the existing surrounding sea state include turbulence generated by the ship, rate of energy input to the short waves from the wind $\left(S_{w}\right)$, rate of energy input from nonlinear interactions among 
longer waves $\left(S_{n l}\right)$, attenuation rate of the short waves by ship-generated turbulence $\left(S_{t}\right)$, and attenuation of the waves by viscosity $\left(S_{v}\right)$. One reason for interest in these short waves is that they are responsible for Bragg scattering of radar and show up as dark streaks in radar images.

The influences on short wave attenuation and growth, in regard to the source terms $(S)$ described above, can be assessed with a model based on the spectral energy balance equation (Hasselmann 1960, Snyder et al. 1981):

$$
\frac{\partial E(\vec{k})}{\partial t}+\vec{c}_{g}(\vec{k}) \cdot \nabla E(\vec{k})=S_{w}(\vec{k})+S_{n l}(\vec{k})-S_{t}(\vec{k})-S_{v}(\vec{k}),
$$

where $E$ is the wave-number energy density spectrum, $t$ is the time, and $c_{g}(\vec{k})$ is the group velocity for its spectral component.

The passage of the ship nearly obliterates the short waves at the start of the centerline wake, which we take to be about one ship length aft of the ship. This provides an initial condition of $E(\vec{k})=0$ for integrating the energy balance equation for a prescribed value of $\vec{k}$. The approach, then, is to generate semiempirical models for the source terms.

\subsection{Model for the Spectral Energy Source Terms Outside the Wake}

To integrate the energy balance (Equation 20), mathematical models for the source terms are necessary. The approach taken by Milgram et al. (1993b) was to develop a model to be used outside the wake and to add corrective terms to this model inside the wake. The model outside the wake is equivalent to the ones used by Lyzenga \& Bennett (1988) and Lyzenga (1991). It is supported by the findings of Plant (1982) that state when $E(\vec{k})$ is less than its equilibrium value, $E_{0}(\vec{k})$, the rate of increase of $E$ is proportional to $E$ itself. This leads to the model

$$
S_{w}(\vec{k})+S_{n l}(\vec{k})-S_{t}(\vec{k})-S_{v}(\vec{k})=\beta(\vec{k}) \frac{E(\vec{k})}{E_{0}(\vec{k})}\left[E_{0}(\vec{k})-E(\vec{k})\right]
$$

Plant (1982) developed the following semiempirical formula for $\beta$ :

$$
\beta(\vec{k})=(0.04 \pm 0.02) \omega(k)\left(\frac{u_{*}}{c_{p}(k)}\right)^{2} \cos \theta
$$

where $\theta$ is the angle between the wind, $\vec{k}, k=|\vec{k}|, \omega$ is the circular wave number, and $u_{*}$ is the friction velocity of the wind. For subsequent examples, we use 0.04 as the constant in Equation 22, and $u_{*}$ is taken as 0.04 times the wind speed at a height of $10 \mathrm{~m}$. 


\subsection{Model for the Source Terms Inside the Wake}

The model used in the wake is taken as

$$
\begin{aligned}
& S_{w}(\vec{k})+S_{n l}(\vec{k})-S_{t}(\vec{k})-S_{v}(\vec{k}) \\
& \quad=\beta(\vec{k}) \frac{E(\vec{k})}{E_{0}(\vec{k})}\left[E_{0}(\vec{k})-E(\vec{k})\right]-S_{w t}(\vec{k})-S_{s}(\vec{k})+S_{w n l}(\vec{k}),
\end{aligned}
$$

where $S_{w t}$ and $S_{s}$ are the additional spectral energy loss rates due to ship-generated turbulence and surface films and $S_{w n l}$ is additional nonlinear energy transfer.

Olmez \& Milgram (1992) conducted a series of experiments leading to a formula for the damping of short waves by turbulence:

$$
S_{w t}(\vec{k})=0.06 \frac{u^{\prime} k^{2 / 3}}{L^{1 / 3}} E(\vec{k}),
$$

where $u^{\prime}$ is the rms velocity of one component of the ship-generated horizontal turbulence, which is presumed to be horizontally, but not vertically, isotropic. $L$ is the integral length scale of this turbulence component defined as

$$
L \equiv \frac{\pi}{2} \frac{\Phi(0)}{\left(u^{\prime}\right)^{2}},
$$

where $\Phi(k)$ is the one-sided power density spectrum of $u^{\prime}$.

The wakes of ships moving at low to moderate Froude number have very little net momentum for which the widths increase as $x^{1 / 5}$ and velocities decrease as $x^{-4 / 5}$ where $x$ is the distance aft (Birkhoff \& Zarantonello 1957, Chapter 14). In 1989, we measured wake widths on transverse lines across the wakes of several naval vessels, assuming the widths corresponded to the widths of zones of altered surface tension (Milgram et al. 1993a). Figure 12 shows all of these data as well as a line with an $x^{1 / 5}$ behavior of arbitrary origin. The individual wake widths are very nearly parallel to this line.

Hoekstra \& Ligtelijn (1991) conducted an extensive series of experiments on the wakes of ship models that were $5 \mathrm{~m}$ long. Figure 13 shows the maximum normalized rms turbulence intensity versus distance aft of the stern in the wakes of several of their models. The measured data are shown by crosses and the solid line is the curve fit:

$$
\frac{s^{\prime}}{U}=\frac{0.05}{\left(x / L_{s}+0.07\right)^{4 / 5}} .
$$

Figure 14 shows the cross-wake turbulence intensity distribution measured by Hoekstra \& Ligtelijn and a parabolic fit to this function. It is slightly off-center, but its centered version is used for the source term $S_{w t}$. The peak surface turbulence intensity is taken as $73 \%$ of the peak measured in the experiments, to be consistent with the fact that this peak occurred some distance beneath the surface.

The strong turbulence immediately behind the ship dissipates or scatters the short waves (Phillips 1958). However, as the turbulence rapidly reduces with 


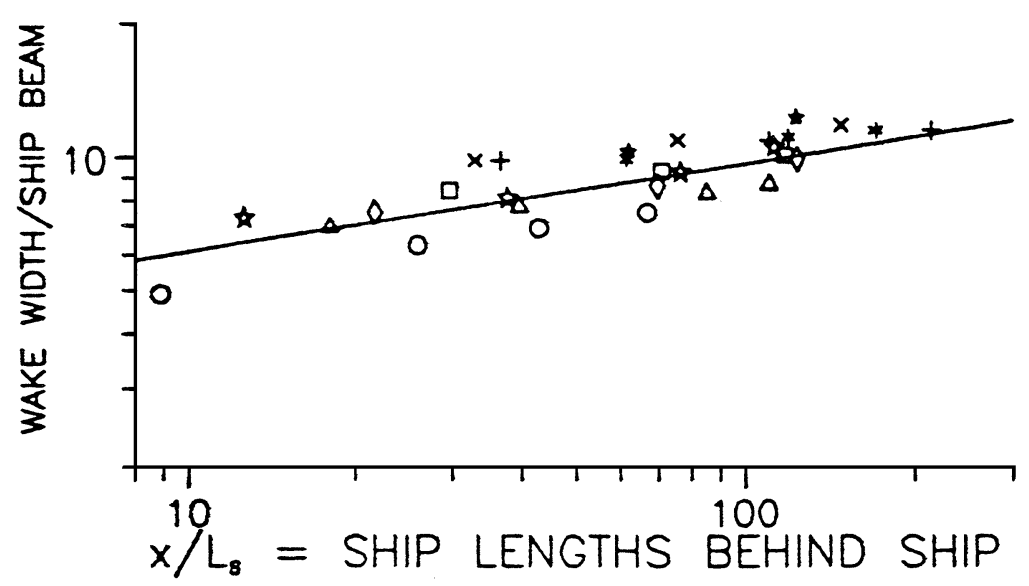

Figure 12 Measured wake widths. Each symbol type corresponds to a different wake (from Milgram et al. 1988b).

increasing aft distance, it has little additional effect on the waves in the wake that are more than approximately one ship length behind the ship. The effect of the wake on the nonlinear energy transfer from long waves to short waves is not well understood. Some of what is known is based on the work of Alpers \& Huhnerfuss (1989). They used knowledge about the damping of specific wave lengths by surfactants and made inferences from the effects on other wavelengths. This analysis is summarized by Milgram et al. (1993b), who also examined the sensitivity of

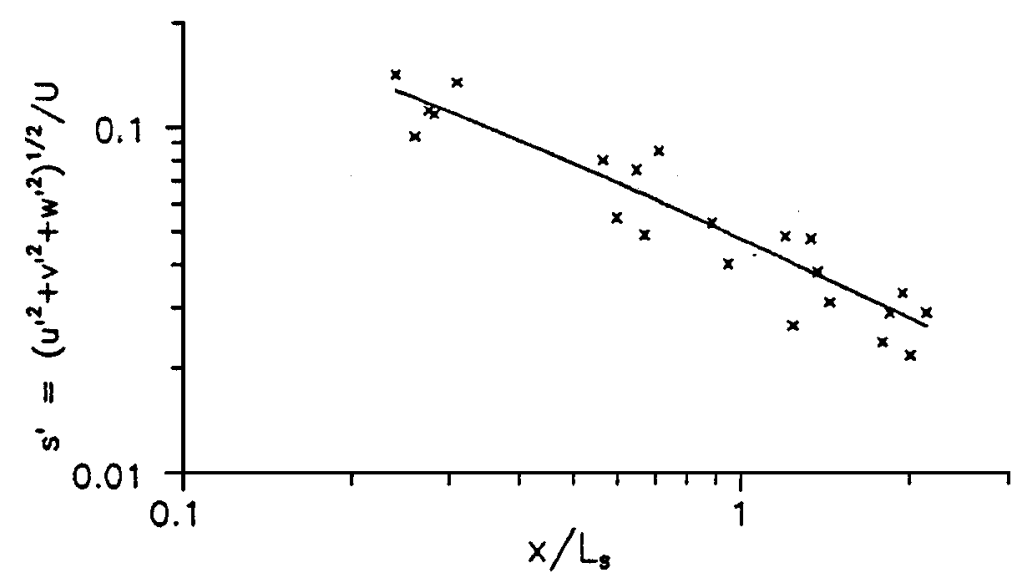

Figure 13 Maximum turbulence intensity versus distance aft in the Hoekstra \& Ligtelijn experiments. $U$ is the ship speed; $L_{s}$ is the ship length (from Milgram et al. 1988b). 


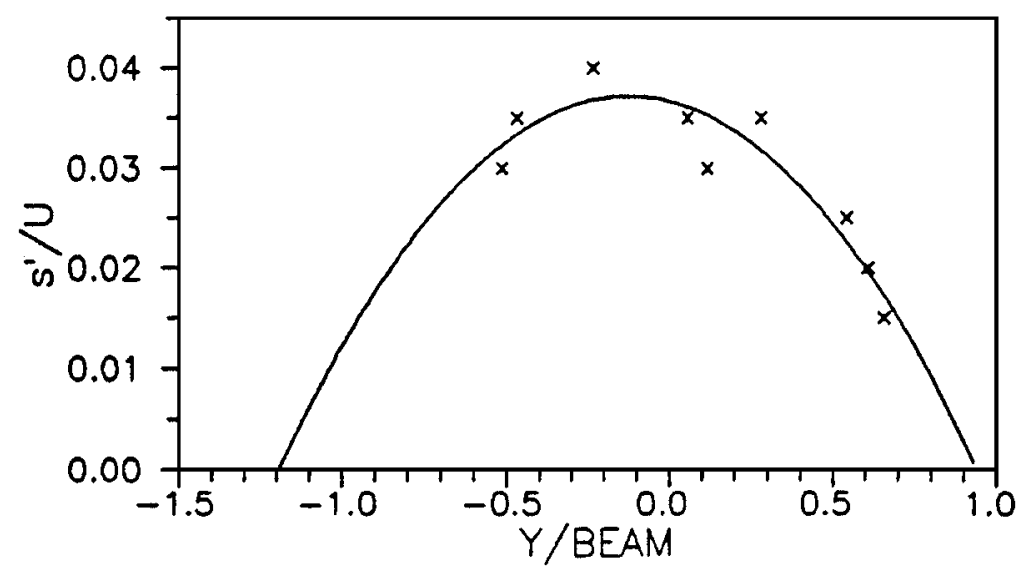

Figure 14 Cross-wake turbulence intensity distribution (measured by Hoekstra \& Ligteljin) and its parabolic fit (from Milgram et al. 1988b).

results to its magnitude. The effect is small, and for subsequent examples here, this source term, $S_{w n l}$, is set to zero.

Many regions of the ocean surface contain surfactant molecules. In the deep ocean the principal sources of surfactants are phytoplankton exudate and the chemical breakdown of dead organisms (Zutic et al. 1981, Bock \& Frew 1993). In coastal regions the surfactant concentration can be increased by sewers and land runoff. In some locations the surface concentration is sufficient to generate a contiguous monolayer or even more surfactant. These surfactant layers are commonly referred to as surface films. Contiguous surface-film layers can be detected because they have lower surface tension. Generally the surface tension diminishes monotonically with increasing surfactant concentration. In the open sea, a more common condition is that the surface concentration is too low to form a contiguous monolayer. These layers can exist in stable form only when the wind is light enough for the sea surface to have little mixing by wave breaking.

When a ship moves through a region, the surface flow from breaking bow and stern waves can have convergence zones that concentrate the surfactant. Roth et al. (1999) present details of the flow structure and turbulence in a breaking bow wave of a ship model. It is well known that the viscoelastic properties of surface films have a major influence on the viscous damping of short gravity and gravity-capillary waves. The literature on this subject is vast. Three examples are Dorrestein (1951), Hansen \& Ahmad (1971), and Cini \& Lombardini (1978).

The persistence of the ship-induced zones of increased surface-film concentration can exceed $1 \mathrm{~h}$ in light wind conditions. Figure 15 shows measurements, made by Peltzer et al. (1992), of surface tension versus cross-wake position for distances in excess of $21 \mathrm{~km}$ aft of a moving ship. An L-band SAR image of the same wake was shown by Milgram et al. (1993a) and is reproduced in Figure 16. 


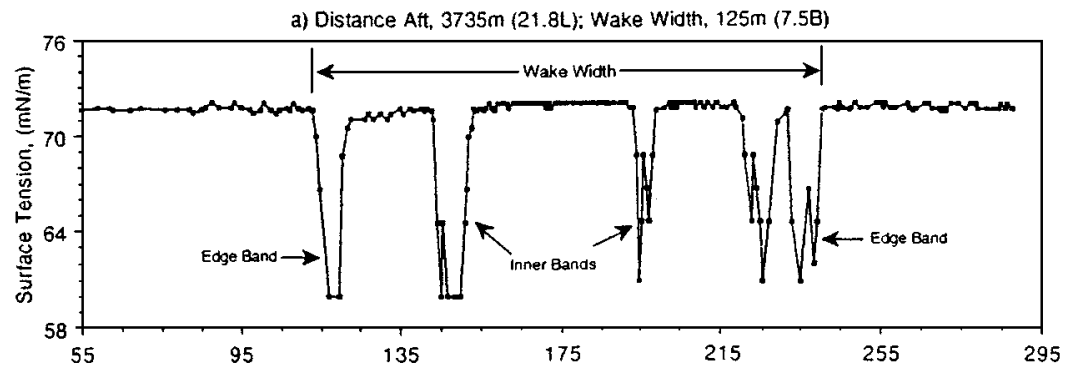

b) Distance Aft, $11978 \mathrm{~m}(69.8 \mathrm{~L})$; Wake Width, $148 \mathrm{~m}(8.8 \mathrm{~B})$

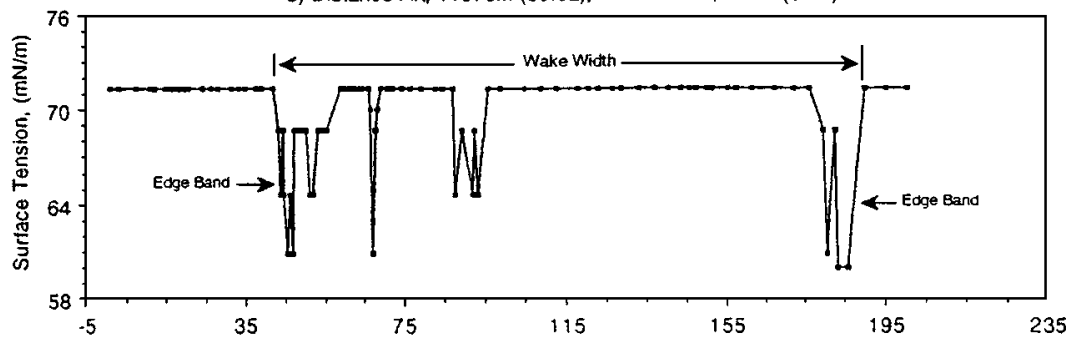

c) Distance Att, $21316 \mathrm{~m}$ (124.2L); Wake Width, $166 \mathrm{~m}(9.9 B)$

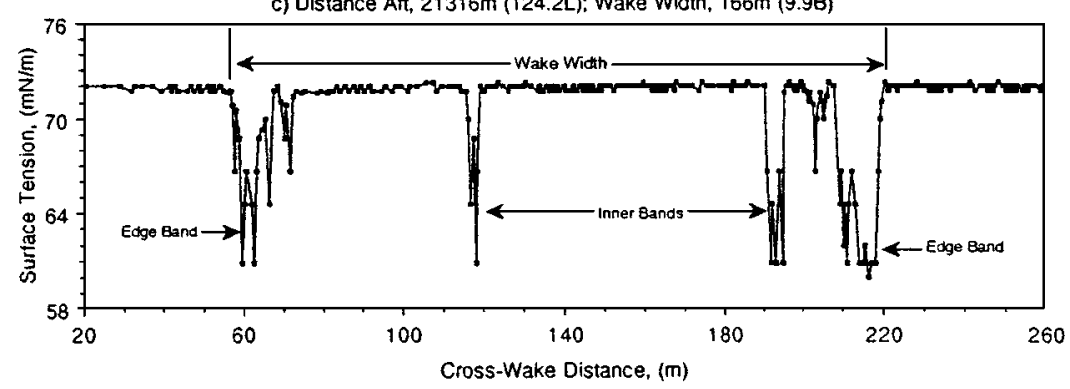

Figure 15 Measured cross-wake surface tension distributions in a ship wake (from Peltzer et al. 1992).

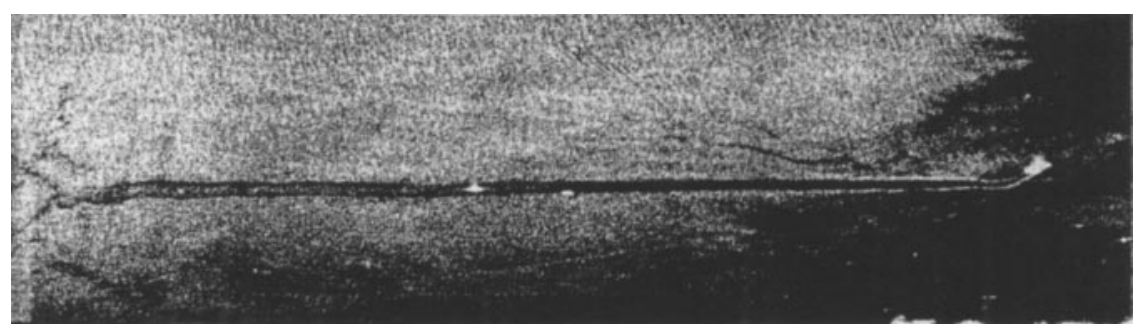

Figure 16 L-band SAR image of a ship wake obtained from an aircraft (courtesy James Lyden). 
The bright spots in the wake are ships making measurements. Milgram et al. (1993b) developed a semiempirical model for the spatial distribution of radarscattering waves in ship wakes. The dominant damping came from the surfactant layers and, some distance downwind from the layers, was required for the waves to regrow. In the portion of the wake furthest from the ship, at the left-hand edge of Figure 16, wave regrowth between the surfactant bands is in evidence by the increased backscattering from the center of the wake.

The wave number-dependent attenuation due to surface films is primarily dependent on the elasticity of the film. In laboratory experiments, Peltzer et al. (1992) measured the relation between the surface tension and the surface elasticity, and these data were used to calculate $S_{S}$.

\subsection{Results of Numerical Modeling}

Milgram et al. (1993b) carried out numerical integrations of Equation 20 using the source term modeling and the measured surface-tension distributions shown in Figure 15. Surface-tension distributions at the beginning of the wake were based on an empirical approach, and interpolation between measurement wake traverses was used to approximate the whole field of surface tension distribution. It is necessary to impose a floor on the lowest allowed spectral level when integrating Equation 20. With the calculations done on the basis of an arbitrary DC level, the spectral level floor was taken as the lowest central depression in the SAR images shown for L-band in Figure 16 made while the surface tensions were being measured. They vary for different values of $k, \mathrm{C}$-band, and L-band and are given in Milgram et al. (1993a). In Figure 17, we reproduce an L-band result at a distance of $3563 \mathrm{~m}$ behind the ship. The SAR image intensities are shown in the figure as well. The

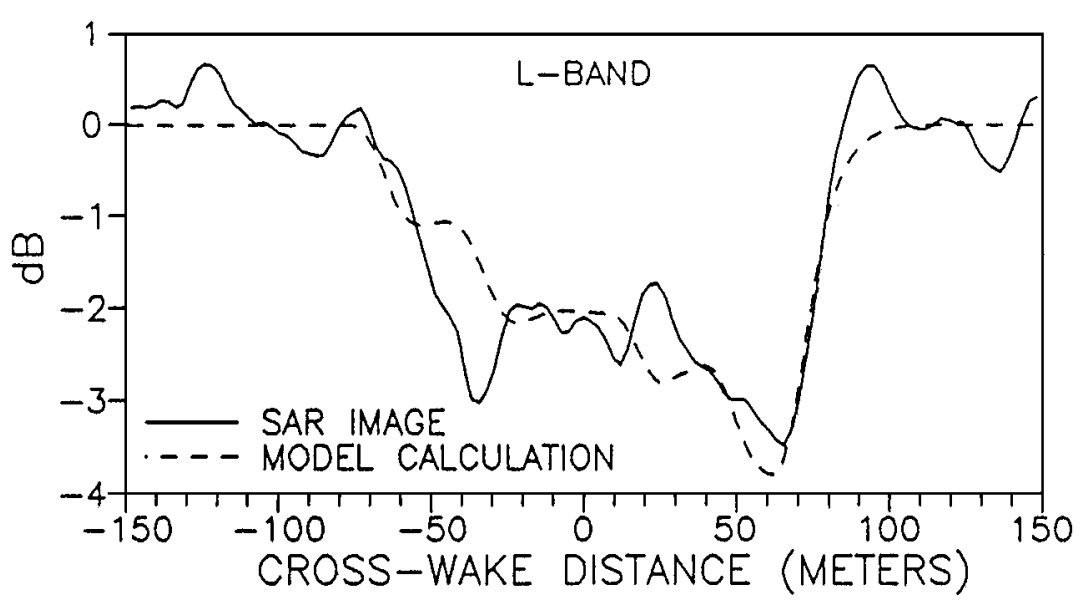

Figure 17 L-band modeled wave energy and SAR intensity distribution $3563 \mathrm{~m}$ behind a ship. 
general correspondence between the modeled wave spectral energy and the SAR image is good.

\section{CONCLUSIONS}

Until radar images of ship wakes were made, especially the images from the SEASAT synthetic aperture radar in 1978, most interest in ship wakes was related to their influence on the resistances of the ships. At that time, details of the Kelvinwake pattern had been quite well known for approximately 100 years. Perhaps the most considered aspect of ship wakes, other than Kelvin wakes, at that time was the long and persistent calm region sometimes observed in centerline wakes under light to moderate wind conditions. The reason for the existence of this calm region was largely unknown.

Then, radar images of ship wakes revealed a number of features that kindled interest in wake morphology. These included observations of $\mathrm{V}$-shaped features of a large range of included angles, centerline dark streaks, and occasional especially persistent wave features, in addition to the Kelvin wake itself. Radar observation of the Kelvin wake could be attributed to the modulation transfer function of the radar backscattering by both the Kelvin-wave surface elevations and the associated currents, but the causes of the other features were unknown.

Research done over the past 20 years has now identified most of the physics associated with image features. In the first few ship lengths behind a ship, the ship-generated currents and turbulence attenuate the short sea waves that are influential in radar back scattering. The flow around the ship and breaking bow and stern waves in particular redistribute surfactants in a way that can have a substantial influence on short wave attenuation. Under many circumstances, the natural ocean surfactant density is too low to support the continuous monolayer required to substantially enhance wave attenuation. However, the flow around the ship and the flows from locally breaking waves can locally compress the surface films into a continuous monolayer that can greatly attenuate the short radar scattering sea waves. Often, these concentrated surfactant bands persist for a long time, on the order of magnitude of $1 \mathrm{~h}$ in light sea conditions, which causes very long, dark, streak centerline radar images. Photographs of the sea surface sometimes show optically these calm regions. The Kelvin waves from some ships operating at a large Froude number are sometimes steep enough for nonlinear effects to create a persistent soliton, which has been observed in some radar images.

Finally, the very narrow bright V-features, with an included angle of just a few degrees, are now known to be Bragg-resonant ship waves, which can come from either the near-centerline part of the diverging Kelvin waves or from unsteady wave generation due to splashing or small amplitude motions of the ship moving with a nearly steady forward speed. 


\section{Visit the Annual Reviews home page at www.AnnualReviews.org}

\section{LITERATURE CITED}

Alpers W, Huhnerfuss H. 1989. The damping of ocean waves by surface films: a new look at an old problem. J. Geophys. Res. 94:51-65

Arabshahi A, Beddhu M, Briley W, Chen J, Gaither A, et al. 1998. A perspective on naval hydrodynamic flow simulations. Proc. Symp. Naval Hydrodyn., 22nd, Washington, DC, pp. 920-34. Washington, DC: Natl. Acad. Press

Beckmann P, Spizzichino A. 1963. The Scattering of Electromagnetic Waves from Rough Surfaces. Oxford: Pergamon. 502 pp.

Birkhoff G, Zarantonello EH. 1957. Jets, Wakes and Cavities. New York: Academic

Bock EJ, Frew NM. 1993. Static and dynamic response of natural multicomponent organic surface films to compression and dilation. $J$. Geophys. Res. 98:599-617

Case K, Dashen R, Munk W, Vesecky J, Watson K, et al. 1985. SEASAT report. Jason Rep. JSR 84-203, Mitre Corp., McLean, Virginia. $211 \mathrm{pp}$.

Cheng BH. 1989. Computations of 3D transom stern flows. Proc. Int. Conf. Num. Ship Hydrodyn., 5th, Washington, DC, pp. 581-92. Washington, DC: Natl. Acad. Press

Cini R, Lombardini PP. 1978. Damping effect of monolayers on surface wave motion in a liquid. J. Colloid Interface Sci. 65:387-89

Cowles G, Martinelli L. 1998. A viscous multiblock flow solver for free-surface calculations on complex geometries. Proc. Symp. Naval Hydrodyn., 22nd, Washington, DC, pp. 445-62. Washington, DC: Natl. Acad. Press

Dawson CW. 1977. A practical computer method for solving ship wave problems. Proc. Intl. Conf. Num. Ship Hydrodyn., 2nd, Berkeley, Calif., pp. 30-38. Berkeley, CA: Univ. Calif. Berkeley

Doctors LJ, Beck RF. 1987a. Numerical aspects of the Neumann-Kelvin problem. J. Ship Res. 31:1-13

Doctors LJ, Beck RF. 1987b. Convergence properties of the Neumann-Kelvin problem for a submerged body. J. Ship Res. 31:22734

Dorrestein R. 1951. General linearized theory of the effect of surface films on water ripples. Proc. Amsterdam Acad. Sci. 54:260-356

Eggers K, Sharma SD, Ward LW. 1967. An assessment of some experimental methods for determining the wave-making characteristics of a ship form. Trans. SNAME 75:112-57

Griffin OM, Peltzer RD, Reed AM, Beck RF. 1992. Remote sensing of ship wakes. Naval Eng. J. 104:245-58

Hall RE. 1991. Solitons in ship wakes. In $O f$ Fluid Mechanics and Related Matters, ed. R Salmon, D Betts. San Diego, CA: Scripps Inst. Oceanogr.

Hall RE, Loeser DJ, Wyatt DC. 1987. A model for the short wavelength portion of a surface wake of a ship and comparison with observations. Tech. Rep. SAIC-87/1794, Sci. Appl. Intl. Corp., San Diego, Calif.

Hammond RR, Buntzen RR, Floren EE. 1985. Use of ship wake patterns in the evaluation of sar ocean wave imaging mechanisms. Joint US-Can. Ocean Wave Investig. Proj., Tech. Rep. 978, Naval Ocean Syst. Cent., San Diego, Calif.

Hansen RS, Ahmad J. 1971. Waves at interfaces. In Progress in Surface and Membrane Science, ed. J Daniell, M Rosenburg, D Cadenhead, 4:1-56. San Diego, CA: Academic

Hasselmann K. 1960. Grundleichungen der seegangsvoraussage. Schiffstechnik 7:191-95

Haussling HJ, Miller RW, Coleman RM. 1997. Computation of high-speed turbulent flow about a ship model with a transom stern. In Proc. 1997 ASME Fluids Eng. Div. Summer Meet. $6 \mathrm{pp}$.

Havelock TH. 1908. The propagation of groups of waves in dispersive media, with application to waves on water produced by a travelling disturbance. Proc. R. Soc. Lond. Ser. A 81:398-430 
Havelock TH. 1934. Wave patterns and wave resistance. Trans. Inst. Nav. Arch. 76:43046

Hess JL, Smith AMO. 1964. Calculation of non-lifting potential flow about arbitrary three-dimensional bodies. J. Ship Res. 8:2244

Hoekstra M, Aalbers A. 1996. Macro wake measurements for a range of ships. Proc. Symp. Naval Hydrodyn., 21st, Trondheim, Norway, pp. 278-90. Washington, DC: Natl. Acad. Press

Hoekstra M, Ligtelijn JT. 1991. Macro Wake Features of a Range of Ships. Wageningen, The Netherlands: Marit. Res. Inst.

Hogner E. 1923. A contribution to the theory of ship waves. Ark. Mat. Astr. Fys. 17:1-49

Kaiser JAC, Ramberg SE, Peltzer RD, Andrews MD, Garrett WD. 1988. A ship wakel films exploratory experiment. NRL Memo. Rep. 6270, US Naval Res. Lab., Washington, DC

Kim Y-H, Kim SH, Lucas T. 1989. Advanced panel method for ship wave inviscid flow theory (SWIFT). DTRC Ship Hydromech. Dep. $R \& D$ Rep. DTRC-89/029, NSWCCD, West Bethesda, Maryland. 66 pp.

Lamb H. 1945. Hydrodynamics. New York: Dover. 738 pp.

Lyden JD, Hammond RR, Lyzenga DR, Schuchman RA, Kasischke ES. 1988. Synthetic aperture radar imaging of surface ship wakes. J. Geophys. Res. 93:293-303

Lyzenga DR. 1991. Interaction of short surface and electromagnetic waves with ocean fronts. J. Geophys. Res. 96:765-72

Lyzenga DR, Bennett JR. 1988. Full-spectrum modeling of synthetic aperture radar internal wave signatures. J. Geophys. Res. 96:34554

Mei CC. 1983. The Applied Dynamics of Ocean Surface Waves. New York: Wiley. 740 pp.

Milgram JH. 1988. Theory of radar backscatter from short waves generated by ships, with application to radar (SAR) imagery. J. Ship Res. 32:54-69

Milgram JH, Peltzer RD, Griffin OM. 1993a. Suppression of short sea waves in ship wakes: measurements and observations. J. Geophys. Res. 98:7,103-14

Milgram JH, Skop RA, Peltzer RD, Griffin OM. 1993b. Modeling short sea wave energy distributions in the far wakes of ships. J. Geophys. Res. 98:7115-24

Munk WH, Scully-Power P, Zachariasen F. 1987. The Bakerian lecture 1986: ships from space. Proc. R. Soc. Lond. Ser. A 412:23154

Nathanson FE. 1969. Radar Design Principles. New York: McGraw-Hill. 626 pp.

Newman JN. 1970. Recent research on ship wakes. Proc. Symp. Naval Hydrodyn., 8th, Pasadena, Calif., pp. 519-45, Arlington, VA: Off. Naval Res.

Newman JN. 1977. Marine Hydrodynamics. Cambridge, MA: MIT Press. 402 pp.

Newman JN. 1987a. Evaluation of waveresistance Green function. Part 1. The double integral. J. Ship Res. 31:79-90

Newman JN. 1987b. Evaluation of the waveresistance Green function. Part 2. The single integral on the centerplane. J. Ship Res. 31:145-50

Noblesse F. 1981. Alternative integral representations for the Green function of the theory of ship wave resistance. J. Eng. Math. 15:24165

Olmez HS, Milgram JH. 1992. An experimental study of attenuation of short water waves by turbulence. J. Fluid Mech. 239:133-56

Peltzer RD, Griffin OM, Barger WR, Kaiser JAC. 1992. High-resolution measurements of surface-active film redistribution in ship wakes. J. Geophys. Res. 97:5,231-52

Peters AS. 1949. A new treatment of the ship wave problem. Comm. Pure Appl. Math. 2: 123-48

Phillips OM. 1958. The scattering of gravity waves by turbulence. J. Fluid Mech. 5:17792

Plant WJ. 1982. A relationship between wind stress and wave slope. J. Geophys. Res. 87: 961-67

Raven HC. 1996. A Solution Method for the Nonlinear Ship Wave Resistance Problem. Wageningen, Netherlands: Marin. 220 pp. 
Raven HC. 1998. Inviscid calculations of ship wave making - capabilities, limitations, and prospects. Proc. Symp. Naval Hydrodyn., 22nd, Washington, DC, pp. 738-54. Washington, DC: Natl. Acad. Press

Reed AM, Beck RF, Griffin OM, Peltzer RD. 1990a. Hydrodynamics of remotely sensed surface ship wakes. Trans. SNAME 98:31963

Reed AM, Telste JG, Scragg CA. 1990b. Analysis of transom stern flows. Proc. Symp. Naval Hydrodyn., 18th, Ann Arbor, Michigan, pp. 207-19. Washington, DC: Natl. Acad. Press

Roth GI, Mascenik DT, Katz J. 1999. Measurements of the flow structure and turbulence within a ship bow wave. Phys. Fluids 11:512-23

Schurmann SR. 1989. Radar characterization of ship wake signatures and ambient ocean clutter features. Proc. 1989 IEEE Natl. Radar Conf., Dallas, Texas, pp. 182-87. Piscataway, NJ: IEEE

Sclavounos PD, Nakos DE. 1988. Stability analysis of panel methods for free-surface flows with forward speed. Proc. Symp. Naval Hydrodyn., 17th, The Hague, Netherlands, pp. 173-93. Washington, DC: Natl. Acad. Press

Sclavounos PD, Nakos DE. 1990. Ship motions by a three-dimensional Rankine panel method. Proc. Symp. Naval Hydrodyn., 18th, Ann Arbor, Mich., pp. 21-40. Washington, DC: Natl. Acad. Press

Scorpio SM. 1997. Fully nonlinear ship-wave computations using a multipole accelerated, desingularized method. $\mathrm{PhD}$ thesis. Dep. Naval Arch. Marine Eng., Univ. Mich., Ann Arbor, Mich. 106 pp.

Scragg CA. 1999. On the use of free-surface distributions of Havelock singularities. Proc. Intl. Workshop Water Waves Float. Bodies, 14th, Port Huron, Mich., 4 pp. Ann Arbor, MI: Univ. Mich., Dep. Naval Architect. Marine Eng.

Scragg CA, Talcott JC. 1990. Numerical solution of the "Dawson" free-surface problem using Havelock singularities. Proc. Symp.
Naval Hydrodyn., 18th, Ann Arbor, Mich., pp. 259-71. Washington, DC: Natl. Acad. Press

Snyder RL, Dobson FW, Elliott JA, Long RB. 1981. Array measurements of atmospheric pressure fluctuations above surface gravity waves. J. Fluid Mech. 102:1-59

Speziale C. 1992. A review of Reynolds stress models for turbulent shear flows. Proc. Symp. Naval Hydrodyn., 20th, Santa Barbara, Calif., pp. 835-55. Washington, DC: Natl. Acad. Press

Stoker JJ. 1957. Water Waves. New York: Interscience. $567 \mathrm{pp}$.

Subramani AK. 2000. Computations of highly nonlinear free-surface flows, with applications to arbitrary and complex hull forms. PhD thesis. Dep. Naval Arch. Marine Eng., Univ. Mich., Ann Arbor, Mich. 127 pp.

Swean TF Jr. 1987. Numerical simulations of the wake downstream of a twin-screw destroyer model. NRL Memo. Rep. 6131, US Naval Res. Lab., Washington, DC. 41 pp.

Telste J, Reed AM. 1993. Calculation of transom stern flows. Proc. Intl. Conf. Num. Ship Hydrodyn., 6th, Iowa City, Iowa, pp. 79-92. Washington, DC: Natl. Acad. Press

Thompson W. 1887a. On ship waves. Proc. Inst. Mech. Eng. Reprint. 1891. In Popular Lectures and Addresses, 3:450-500. London: MacMillan

Thompson W. 1887b. On the waves produced by a single impulse in water of any depth, or in a dispersive medium. Proc. R. Soc. Lond. Ser. A 42:80-85

Tuck EO. 1990. Planing surfaces. In Numerical Solution of Integral Equations, ed. M Goldberg, pp. 363-72. New York: Plenum

Ulaby FT, Moore RK, Fung AK. 1982. Microwave Remote Sensing-Active and Passive. Volume II. Radar Remote Sensing and Surface Scattering and Emission Theory. Reading, MA: Addison-Wesley. 1064 pp.

Ursell F. 1960. On Kelvin's ship-wave pattern. J. Fluid Mech. 8:418-31

van Manen JD, van Oossanen P. 1988. Resistance. In Principles of Naval Architecture, Vol.II. Resistance, Propulsion and Vibration, 
ed. EV Lewis, pp. 1-125. Jersey City, NJ: Soc. Naval Archit. Mar. Eng. 327 pp.

Vesecky JF, Stewart RH. 1982. The observation of ocean surface phenomena using imagery from the SEASAT synthetic aperture radar: an assessment. J. Geophys. Res. 87:397430

Wehausen JV. 1963. An approach to thin-ship theory. In International Seminar on Theoretical Wave-Resistance, pp. 821-55. Ann Arbor, MI: Univ. Mich.

Wehausen JV. 1973. The wave resistance of ships. In Advances in Applied Mechanics, ed. C-S Yih, 13:93-245. New York: Academic

Wehausen JV, Laitone EV. 1960. Surface waves. In Handbuch der Physik, 9:446-778. Berlin: Springer-Verlag

Wigley C, ed. 1965. The Collected Papers of Sir
Thomas Havelock on Hydrodynamics. Washington, DC: Off. Naval Res.

Wilson R, Paterson E, Stern F. 1998. Unsteady RANS CFD method for naval combatants in waves. Proc. Symp. Naval Hydrodyn., 22nd, Washington, DC, pp. 532-49. Washington, DC: Natl. Acad. Press

Wyatt DC. 2000. Development and assessment of a nonlinear wave prediction methodology for surface vessels. J. Ship Res. 44:96-107

Yih C-S, Zhu S. 1989a. Patterns of ship waves. Q. Appl. Math. 47:17-33

Yih C-S, Zhu S. 1989b. Patterns of ship waves II, gravity-capillary waves. Q. Appl. Math. 47:35-44

Zutic VB, Cosovic B, Marcenko E, Bihari N. 1981. Surfactant production by marine phytoplankton. Mar. Chem. 10:505-20 


\section{CONTENTS}

FRONTISPIECE

Xii

MiLTON VAN DYKE, THE MAN AND HIS WORK, Leonard W. Schwartz

G.K. BATCHELOR AND THE HOMOGENIZATION OF TURBULENCE, H.K. Moffatt

DAVID CRIGHTON, 1942-2000: A COMMENTARY ON HIS CAREER AND His INFLUENCE ON AEROACOUSTIC THEORY, John E. Ffowcs Williams

Sound Propagation Close to the Ground, Keith Attenborough

ELLIPTICAL INSTABILITY, Richard R. Kerswell

LAGRANGIAN INVESTIGATIONS OF TURBULENCE, P.K. Yeung

CAVITATION IN VORTICAL Flows, Roger E.A. Arndt

Microstructural Evolution in Polymer Blends, Charles L.

Tucker III and Paula Moldenaers

Cellular Fluid Mechanics, Roger D. Kamm

DYNAMICAL PHENOMENA IN LIQUID-CRYSTALLINE MATERIALS, Alejandro D. Rey and Morton M. Denn

NoncoAlescence AND Nonwetting Behavior of LiQuids, $G$. Paul Neitzel and Pasquale Dell' Aversana

BOUNDARY-LAYER RECEPTIVITY TO FREESTREAM DISTURBANCES, William S. Saric, Helen L. Reed, and Edward J. Kerschen

OnE-Point Closure Models For BuOYANCY-Driven TuRbulent Flows, K. Hanjalić

Wall-Layer Models for Large-Eddy Simulations, Ugo Piomelli and Elias Balaras

FILAMENT-STRETCHING RHEOMETRY OF COMPLEX FLUIDS, Gareth $H$. McKinley and Tamarapu Sridhar

MoleCUlar ORIENTATION EFFECTS IN VisCOElasticity, Jason K.C. Suen, Yong Lak Joo, and Robert C. Armstrong

THE RICHTMYER-MESHKOV INSTABILITY, Martin Brouillette

SHIP WAKES AND THEIR RADAR IMAGES, Arthur M. Reed and Jerome H. Milgram 
SyNTHETIC JETS, Ari Glezer and Michael Amitay

FluID DYNAMICS OF El NiÑO VARIABILITY, Henk A. Dijkstra and

Gerrit Burgers

INTERNAL GRAVITY WAVES: FROM INSTABILITIES TO TURBULENCE,

C. Staquet and J. Sommeria

INDEXES

Subject Index

Cumulative Index of Contributing Authors, Volumes 1-34

Cumulative Index of Chapter Titles, Volumes 1-34

\section{ERRATA}

An online log of corrections to the Annual Review of Fluid Mechanics chapters may be found at http://fluid.annualreviews.org/errata.shtml 